\title{
Virtual reality-based cognitive healthcare interventions: User-centered design considerations, guidelines and framework
}

\author{
Rebeca I. García-Betances*®D, María F. Cabrera-Umpiérrez, and María T. Arredondo Waldmeyer \\ LifeSTech, Department of Photonics and Bioengineering, Escuela Técnica Superior de Ingenieros de Telecomunicación, \\ Universidad Politécnica de Madrid, 28040 Madrid, SPAIN.
}

\section{ABSTRACT}

\begin{abstract}
Design of computer-based non-pharmacological cognitive healthcare interventions for people afflicted by chronic neurodegenerative impairments must be soundly informed by and clearly centered on users' distinctive disabilities. In this article we present a use-oriented analysis of those cognitive interventions intended for healthcare of patients with Alzheimer's dementia and related disorders that use human-computer interaction based on virtual reality technology. The analysis identifies the most important strengths and weakness, and describes and assesses the main key opportunities and challenges inherent to the use of this type of cognitive healthcare interventions. The most critical specific usability concerns that considerably affect these interventions are described in order to be directly addressed during a user-centered design process. Significant evaluation issues that still trouble these interventions' general acceptance are also included. On the basis of this analysis, appropriate actions are recommended to help minimize accessibility and usability issues. Finally, concrete design guidelines, and a framework with its road map are proposed to direct the design process. The proposed framework's more outstanding features and functionalities are described in relation to user-centered design conceptualization, implementation and assessment. The use of a consistent usercentered design methodology, such as the one proposed here to tackle the main critical obstacles, could turn out to become the key that allows to achieve a substantial improvement of VR-based cognitive healthcare interventions effectiveness.
\end{abstract}

Keywords: Computerized cognitive healthcare, Virtual reality for healthcare, Non-pharmacological cognitive healthcare, Alzheimer's dementia.

\section{Introduction}

The number of people affected worldwide by different forms of dementia represents from 5 to $8 \%$ of the total population, presently corresponding to an estimate of around 50 million. Both of these numbers are rising rapidly because of increasing longevity in most countries and global population growth, respectively. The most common form of dementia is Alzheimer's disease (AD), which according to the World Health Organization (WHO) accounts for between 60 and $70 \%$ of all cases. AD is a progressive neurodegenerative syndrome, clinically typified by gradual cognitive decline, increasing memory loss, growing functional disability, and often accompanied by behavioral and psychological symptoms of dementia (BPSD) (Kales et al., 2018; Loi et al., 2018), such as disorientation, mood swings, agitation, aggression, delusions, hallucinations, delirium, etc. (Drew, 2018). AD and its related disorders (ADRD), such as mild cognitive impairment (MCI), inflict enormous human suffering and imposes heavy economic burdens on the affected individuals and their families. The high worldwide incidence of AD together with the gravity of its consequences on Society in general constitutes a serious public health challenge around the globe.

The search for pharmacological treatments for AD proceeds at an extraordinary pace, and new promising developments are announced almost daily, but, as yet, none has been found that is effective enough to biologically cure AD or that can significantly change its course. While the quest continues, non-pharmacological cognitive and behavioral healthcare interventions are being intensively researched for preventive, amelioration and rehabilitation purposes (Raggi et al, 2017). Psychosocial interventions are used for improving cognition or slowing the progression of cognitive impairment in ADRD patients (Duan et al., 2018). These interventions fall within a holistic view of non-pharmacological AD therapy based on the ideas of the brain's cognitive reserve and resilience that relies on keeping patients mentally and physically active (Carrión et al., 2018; Gravitz, 2018). In fact, it is widely recognized today by many that improving potentially modifiable behaviors such as involvement in social activities, doing physical exercise and keeping a healthy diet, among others, together with an active engagement in cognitive stimulating entertaining or intellectual activities, could help curtail neurodegeneration. Nonpharmacological therapies being developed are mostly intended, not as alternatives, but as convenient ways to indirectly mitigate the burdens of the patients and of the other stakeholders. Cognitive care interventions based on human-computer interaction are among the most promising non-pharmacological therapeutic approaches being researched to deal with the consequences of ADRD (García-Betances et al., 2015a).

Perspectives and challenges of computer-based non-pharmacological cognitive interventions aimed at adults with neurodegenerative cognitive disabilities were recently scrutinized in the context of the ongoing commercial "brain training" applications controversy (García-Betances et al., 2018). Initial skepticism about computer-based cognitive interventions is 
mostly decreasing. According to many observational studies and most reviews on the subject, there exists abundant encouraging evidence indicating the potential usefulness of computer-based cognitive interventions. Although not yet sufficiently robust, numerous reported positive results exist that strongly suggest the pertinence of pursuing further R\&D efforts to bolster the present capabilities of these computer-based interventions. Clearly defining the cognitive intervention and clearly determining how to measure its efficacy will be decisive for ascertaining the effectiveness of these non-pharmacological computer-based cognitive healthcare therapies (Harvey et al, 2018). Given the positive evidence accumulated so far, we are confident that the key to develop more effective interventions rests upon the utilization of more advanced human-computer interaction (HCI), especially through the use of virtual environments (VE) that exploit the resources offered by emergent virtual reality (VR) platforms (García-Betances et al., 2015a, 2015b; Raggi et al, 2017), as well as by other related evolving technologies, such as augmented (Chang et al., 2016; Hayhurst, 2018) and mixed virtual reality environments (Lokka et al., 2018).

VR technology represents a remarkable HCI resource for computer-based cognitive healthcare interventions. Its ability to deliver three dimensional (3D) dynamically rich multimedia content in a vivid, entertaining and enjoyable way, within a safe multisensory interactive virtual environment makes it ideal for this purpose (Caggianese et al., 2018). Because of such unique characteristics, VR has the capacity to significantly enhance the way computer-based cognitive healthcare interventions are delivered, and, thus, the ability to uncover new possibilities for improving their effectiveness. As VR becomes an increasingly popular, easily available and affordable entertainment technology, it can provide an excellent gateway to explore new paths to advance the field of cognitive health care interventions, as already is happening in other fields of health rehabilitation (Rose et al., 2018).

Before continuing, we wish to mention that the expression "cognitive healthcare," and alike, are used in this article always to refer in short to non-pharmacological computer-based healthcare interventions for people affected by ADRD. Moreover, it is understood that all usually intended aims of these interventions are contemplated in this article; i.e. purposes such as:

- Detection, diagnosis, testing, and prognosis of neurocognitive impairment symptoms during the early stages of $\mathrm{AD}$, as well as subsequent monitoring and follow-up of the course of cognitive decline progression.

- Improvement of the quality of care (QoC) of ADRD patients through the preservation of cognitive health, the and the delay or reduction of its decline, by the use of cognitive training, rehabilitation or stimulation interventions to help mitigate the effects of cognitive disabilities' symptoms.

- Reinforcement of the ADRD patients' skills and abilities to perform executive functions (Serino et al., 2018), to allow them to continue carrying out activities of daily living (ADL), to promote greater patient independence and enjoy a better quality of life (QoL) within an overall "Active and Healthy Ageing" patient care strategy.

- Doing R\&D to search for possible new early functional indicators of ADRD, which could be implemented within novel VR-based instrumental diagnostic and prognostic procedures;

- Developing and testing novel multimodal feedback mechanisms, to be introduced to refine and improve the intervention's own operation and effectiveness, through epistemic iteration.

- To become a source of valuable multidisciplinary information to nourish the knowledge base needed for this technology's future progress.

It is important to keep in mind when developing advanced applications for the elderly population, and more so for those affected by neurocognitive illnesses such as ADRD, a principle that is essential for technology-assisted healthcare, i.e., that the only underlying reason for using any kind of advanced computer or other technology in the delivery of healthcare, ought not be the use of technology per se, but to provide better healthcare. In the case of nonpharmacological neurocognitive healthcare interventions in particular, this translates to providing a more effective HCI, within a sensorially richer and more interactive environment, which hopefully will be able to significantly improve the intervention's experience, allowing the intervention to more effectively express its intended therapeutic or diagnostic potentialities. It is precisely this the only motivation that should lay behind the use of advanced VR-based technology for cognitive healthcare interventions.

The ultimate general aim is to enhance the quality of care (QoC) of ADRD patients by maintaining the overall well-being (García-Betances et al., 2017; Lin et al., 2018) and QoL of both the patients and their caregivers. Even small improvements will have a significant impact on helping reduce the personal, familial and societal burdens caused by ADRD (Ahmed et al., 2018). A good example of this is a recent attempt to prolong independent living of patients with mild AD by the use of VR-based training in the form of a virtual kitchen used to rehabilitate the skills needed to perform ADL (Foloppe et al., 2018; Richard et al., 2018).

Design of VR-based cognitive healthcare interventions faces special challenges, which are not only of a strictly technical nature. The most serious arise from the interaction between the combination of the very peculiar nature of the users (the ADRD patients) and the intervention's specific intended effect on them, and the type of HCI experience modality to be presented during the intervention. Addressing such unique challenges, usually burdens, calls for a sensible user-centered designed-for-the-goal customizable design procedure.

In the following sections we will first present a brief analysis of the use of VR with 3D head mounted display virtual reality (HMD) technology to deliver cognitive healthcare interventions to people affected by ADRD (García-Betances et al., 2015b). Next we will discuss the key challenges (Hayhurst, 2018), accessibility issues (Mondellini et al., 2018) and other specific 
concerns that characterize the use of VR-based technology for this particular cognitive healthcare purpose. Finally and as a result of the analysis, and attending to best practices considerations, we present specific design recommendations tailored to address the particular needs of VR-based interventions for cognitive healthcare of people affected by ADRD. We then propose a methodological design framework to guide the development and design stages, based on the conceptualization of the VR application, the description of user needs and limitations, and the available resources for system implementation, including an adequate evaluation approach.

\section{Analysis of the use of VR technology for cognitive healthcare interventions}

We performed an analysis of VR technology usage in cognitive disabilities healthcare interventions by means of the wellknown methodology of the "Strengths-Weaknesses-Opportunities-Threats" (SWOT) type of analysis, originally proposed by Learned et al, (1969) for business purposes and later elaborated and abundantly used. The reason for using this particular procedure is that if offers a systematic way to identify the key opportunities, weaknesses, challenges and concerns that are most relevant to understand and assess the merits (advantages and drawbacks) of using VR-based technology for this kind of interventions. SWOT-type analysis has been already shown to be a useful tool for appraising alike types of VR-based rehabilitation therapy applications (Rizzo and Kim, 2005).

We analyzed the use of VR technology for non-pharmacological cognitive disabilities care interventions systematically applying the conceptual guidelines and strategies of the above mentioned SWOT methodology (García-Betances, 2017). That analysis provided the basis for identifying potentially desirable strengths and opportunities, as well as for highlighting the inherent weaknesses, threats and challenges of this specific VR design concept. Table I presents the analysis' findings summarized in the form of a "SWOT matrix."

TABLE I

“SWOT” ANALYSis MATRIX OF THE USE OF VR TeChNOLOGY FOR COGNITIVE INTERVENTIONS (García-Betances, 2017).

\begin{tabular}{|c|c|}
\hline $\begin{array}{l}\text { STRENGTHS (Positive factors) } \\
\text { - Immersive and interactive } \\
\text { - Increased motivation and engagement } \\
\text { - Enhanced ecological validity } \\
\text { - Possible enhanced measurable effectiveness } \\
\text { - Real-time \& long-lasting monitoring \& feedback } \\
\text { - Online remote data access } \\
\text { - Enhanced data gathering options; } \\
\text { - Reduced costs. }\end{array}$ & $\begin{array}{l}\text { WEAKNESSES (Negative factors) } \\
\text { - Technology resistance by patients \& caregivers; } \\
\text { - Technological complexity } \\
\text { - Complicated multi-systemic interoperability } \\
\text { - Possible simulation sickness and other physiological } \\
\text { effects }\end{array}$ \\
\hline $\begin{array}{l}\text { OPPORTUNITIES } \\
\text { - High potential for emerging multisensorial technology } \\
\text { - Personalization \& self-adaptiveness } \\
\text { - Real-time data analysis \& immediate feedback } \\
\text { - Improved testing \& training } \\
\text { - Potential for advanced cognitive disabilities care } \\
\text { procedures }\end{array}$ & $\begin{array}{l}\text { THREATS (external threatening factors) } \\
\text { - Relative scientific weakness of presently existing evidence } \\
\text { could affect adoption } \\
\text { - Non-existing or conflicting healthcare regulations and policies } \\
\text { - Interfering commercial business interests }\end{array}$ \\
\hline
\end{tabular}

\section{Outcomes from the analysis}

The SWOT matrix provides concise information needed to accomplish three types of valuable intersecting appraisals: Strengths-Opportunities (SO), Weaknesses-Opportunities (WO), and Threats assessments which should be carried out before engaging in the actual design process (García-Betances, 2017). They are:

\subsection{SO assessment}

External opportunities must be carefully considered during design to be able to take full advantage of the internal strengths inherent to the use of VR technology:

- Developing Technologies: Rapid advances, growth and continuing cost reductions of VR technology inspire the development of more advanced, versatile, user friendly, and affordable VR-based cognitive intervention platforms, including those able to provide at-home cognitive care.

- Improved treatments, procedures and testing environments: There are new opportunities for implementing novel intervention modalities. One example would be the use of odorant delivery devices coordinated with a VR platform for olfactory dysfunction testing, a promising biomarker for detection and diagnosis of preclinical MCI and AD (Lafaille-Magnan et al., 2017; Woodward et al., 2018). Other examples include the combination of VR cognitive interventions to be used concurrently with other types of interventions, such as the preservation of vascular health by VR-driven physical exercise (Doniger et al., 2018). Another possibility is the development of novel mixed modality interventions by integrating into the VR platform any of several existing or emerging minimally invasive neurotechnological procedures, e.g. Transcranial Magnetic Stimulations (tMS) (Nguyen et al., 2017; Marron et al., 2018).

- Ecological validity: The excellent ability to represent real life in highly immersive scenarios allows 3D VR 
technologies to be capable of providing highly realistic customizable dynamic environments.

- Real-time monitoring and feedback: Testing, training and treatment VR platforms should include comprehensive feedback of the patient's performance and vital signals during the intervention, to be used for real-time monitoring purposes and long-lasting data storage. New brain-computer interfaces (BCI) (Coogan and He, 2018), sophisticated brain signal monitoring techniques, as well as novel forms of computational imaging eventually could be adapted to be used in compatible conjunction with VR. Monitoring the brain during the intervention's evolution would allow to dynamically adapt its content to the user's particular performance (e.g. by changing the level of difficulty, reorientation of goals, etc.). Timely intelligent processing and analysis of gathered pertinent brain data would provide important knowledge that could be useful for future intervention design refinement and latter development of other novel diagnostic and treatment procedures (García-Betances et al, 2018). A recent example in this line is the PERSON project (Monaco et al., 2018), a VR-based serious games tool where an electroencephalography (EEG) BCI and haptic devices are used for training cognitive abilities.

- Personalization and self-adaptation: Emerging user-friendly personal devices, together with self-adaptive technologies can serve to adjust the VR intervention to the patient's specific care needs (Vaughan et al., 2016). Immersive 3D HMD-VR platforms (Intraraprasit et al., 2017) complemented as needed by other advanced sensory interfaces and feedback resources, and supported by innovative scientifically sound cognitive software and flexible processing capabilities, such as e.g. artificial intelligence (AI), in general embody the best technological recipe for achieving the most benefits from this type of intervention (García-Betances, 2017). However, the level of success will depend on designing such interventions from the start according to well defined user-centered design (UCD) strategies (Norman and Draper, 1986).

- Motivation and engagement: VR technology in principle has a proven ability to stimulate user motivation. VR motivational potential derives mainly from its ability to provide $3 \mathrm{D}$ vivid representations of natural, or imaginary, scenarios where the patient can be safely immersed in and can realistically interact with. Patient engagement and intervention adherence can be stimulated properly using VR's sensorial resources. To further promote engagement, a number of long-established strategies can be implemented, such as gamification of tasks, reward enticing, challenging chores, collaborative involvement, tutorial guidance, and opportune couching assistance, among many others.

- Cost reduction: Whenever a cognitive intervention needs to be carried out within some special environmental setting or particular scenario, or when it has to mimic some activity of daily living, VR's versatility makes it the delivery platform of choice. Moreover, VR potential portability allows to provide quality home-based cognitive healthcare, thereby reducing travel to specialized centers. Furthermore, the special software used in VR interventions may be duplicated and shared to reduce costs (Rizzo and Kim, 2005).

\subsection{WO assessment}

Some of the possibly harmful weaknesses inherent to VR usability may be lessened by dealing with them early during the design process with the assistance of some external opportunities (García-Betances, 2017). The most prominent are:

- General resistance to technology use. Could be preexisting or arising from the specific impairments or deficits of the ADRD patient. I can possibly be complicated by age- and physical health-related factors and comorbidities.

- Technological complexity. In cognitively impaired patients it might cause overwhelming operative difficulty. It manifests to the user mainly at the interfaces. Thus, it can negatively influence acceptance and trigger unwillingness to use cumbersome gadgets, such as HMDs and other unfamiliar sensorial feedback devices (Schraepen et al., 2017).

- Physiological side effects. Are produced by the VR environment itself. Cyber-illness or motion sickness are the most common. They can be experienced also by cognitively normal people when using highly immersive VR. Considering that in this case these effects would affect patients with cognitive disabilities and possibly frail health, utmost care must be exercised to quickly detect their possible occurrence during the intervention (Kim et al., 2018). Ethical concerns stipulate that effective means be designed-in to prevent or minimize their occurrence (Rizzo et al., 2002).

- Interoperability. Compatibility issues normally arise when trying to put together a design that contains several different types of sophisticated software, dissimilar hardware, and various types of interfaces into an integrated VRbased platform. These issues have to be addressed as early as possible in the design process to be able to produce a VR platform capable of delivering useful multisensory and multimodal interventions (Chalfont et al., 2018) to ADRD patients.

\subsection{Threats (external threatening factors) assessment}

The single major factor that still hinders a wider adoption of computer-based cognitive healthcare intervention in general is a presently insufficient corpus of scientifically solid evidence to support in an unquestionable fashion the real effectiveness claimed of this type of cognitive interventions. This situation is further exacerbated by a lack of common criteria (McCabe et al. 2016; García-Betances et al, 2018). The absence of enough universally consensual standards, definitions, classifications and 
other descriptive measures regarding ADRD in general encumbers proper assessment of results, and hence holds back the development of these non-pharmacological interventions. Scientific rigor weakness of many of the existing, otherwise mostly positive, observational evidence of brain training effectiveness, as well as the still insufficient convincing confirmation of successful far transfer of intervention effects, is severely affecting further progress (García-Betances et al, 2018). Commercial business interests in VR-applications for cognitive health care are important players in the field (Allaire et al., 2014). Most credibility concerns originate from methodological validation problems (Sim9ns et al., 2016). These concerns must be addressed during the design of prototypical VR platforms. Scientifically sound objective evaluation measures must be included using standard methodologies (García-Betances, 2017). Some recommendations to tackle the main issues confronting validation concerns of VR neurocognitive interventions are:

- The merits of the VR-based intervention must be objectively assessed and compared at different levels of immersion with respect to: effectiveness, ease of patient use, technology complexity, needed infrastructure, installation and usage costs, etc.

- The capacity of the VR intervention's outcomes for "far transfer" to different scenarios or tasks must be objectively measured, assessed and compared.

- The long-term endurance of the VR intervention's outcomes must be monitored and carefully analyzed.

- Large-size randomized controlled trials (RCTs) must be performed on any new VR neurocognitive intervention. Scientifically rigorous and reliable safeguards must be included in the trial, ruling out or correcting possible misleading bias, placebo effects, or other experimental artifacts.

Common VR best practices and cognitive care usage-specific guideline principles must be used during the design stage to take full advantage of VR's internal technological strengths to avoid or mitigate the principal external threats. Once in actual use, the VR-based neurocognitive intervention should be kept under rigorous scrutiny and analysis of performance based on long-term monitoring.

\section{Design guidelines}

The preceding SWOT analysis and ensuing assessments provide practical information that allows translating general VR intervention's requirements into concrete tailor-made design specifications (Hodge et al., 2018). Accordingly, we propose a set of guidelines which have been adapted to specifically address the broad range of intended purposes and desired experience modalities representative of most VR-based neurocognitive care interventions for ADRD.

\subsection{General purpose VR design}

There exists an ever increasing amount of information readily available resources which provide software designers with ample guidance and advice for general or brand-specific VR applications. They are beyond the scope of this article. However, we will just mention that most consist of some kind of best practices indications and procedural guidelines, useful for designing different kinds of VR applications, including those intended for cognitive care intervention (García-Betances, 2017).

It is worth mentioning that reliable techniques and tools for testing VR application software (Vos et al., 2012) in general ought to include: 1) a precise conceptualization of the application; 2) modelling of resources and system implementation; and 3) description of the evaluation process and how to carry it out.

\subsection{User-centered design paradigm}

Increasingly complex technological products and systems with sophisticated functionalities, unusual accessibility and interfaces, and user comprehension problems, can produce usability gaps between a user's technical knowhow and the product's high complexity. The designer's challenge is to reduce those gaps by focusing on end users' relative needs, characteristics, and limitations during the design process.

Computers today are an integral part of ordinary elderly people's lives, even of those individuals with disabilities. On the other hand, many late life human functional impairments are caused by disabilities that normally show up and increase with age. Consequently, researchers and developers of computer-based applications aimed at the elderly population must utilize adequate design methodologies that pay exceptional attention to the specific needs imposed by such particular disabilities (Wagner et al., 2010).

Personalization and users' self-customization design paradigms can be very useful within inclusive strategies that try to address the particular needs of users with disabilities (Hendricks, 2007; Wagner et al., 2010; García-Betances et al., 2016). Many serious design challenges are related to usability issues arising from users' physical, cognitive and behavior functional limitations, and reduced abilities in general, which can significantly affect user acceptance and adherence (Eberle et al., 2011; LeRouge et al., 2013; Schraepen et al., 2017; da Costa et al., 2018).

Both the elderly and people with disabilities have needs and concerns distinct from those of ordinary users, which are often disregarded during development and design (LeRouge et al., 2013). Nonetheless, there have been studies and actions (Newell and Gregor, 1997; Alm and Nakamura, 2001; Gregor et al., 2002; Ferreira et al., 2014) focused on overcoming some of the technological barriers faced by users affected by various impairments or limitations. 
There exists an ample corpus of reported work done specifically on VR-based interventions intended to provide cognitive care to people with ADRD derived impairments (García-Betances et al, 2015a; 2015b; 2018). Based on that accumulated experience we propose the adoption of a user-centered designed-for-the-goal customizable design type of approach for the design of these interventions (García-Betances, 2017). Such approach frees the designer from the need of making use of speculative suppositions and uncertain estimates. Additionally, it has become obvious by now that in order to be successful, the design process must be dependent upon iterative re-evaluation. An iterative design approach is necessary to attain high usability levels and user acceptance. The chief characteristic, therefore, is that the design process places end-users (patients and caregivers in this case) at the center of the design process, following the strategy of what has come to be commonly known as UCD (Norman and Draper, 1986).

UCD for Human-Computer Interaction (HCI) is a design methodology based on inquires, assumptions, and analysis of users' needs, desires, and limitations useful for designing computer-based applications (LeRouge et al., 2013). Various user modelling techniques that typify groups of users may be used, i.e.: feature-, content-, case-, scenario-, and knowledge-based; goal-, demographic-oriented, etc. (Gregor et al., 2002; Kurschl et al., 2014). In spite of the potential benefits offered by UCD methodologies, their use within the healthcare technology field has not yet received the attention it deserves (LeRouge et al., 2013). The same can be said of applications for the elderly. Existing technical literature in general provides insufficient guidance on how to involve older people in the design process, although there have been some studies that do focus on this population segment (Ferreira et al., 2014).

UCD has been used for designing cognitive supportive health applications for the elderly (Harte et al., 2014). The design of assistive technologies (Dubey et al., 2014) in general benefits from UCD because of its inclusion of users' needs, goals, and abilities, and because it strives to account for users' vital contextual experiences. A fundamental aspect of HCI design for being able to provide support to patients with disabilities (Newell and Gregor, 1997) is user modeling. Thus, it represents the key resource of UCD methodology (Fischer, 2001; Casas et al., 2008; Castillejo et al., 2014a).

Analysis of various experiences with VR-based cognitive healthcare interventions convincingly suggests that it is not enough for the purpose of UCD of this type of HCI to classify patients merely according to their capabilities. The specific deficiencies that impair these particular patients' capabilities (Gregor et al., 2002) must be taken into careful consideration. Explicit aspects that need to be considered are those related mainly to the patients': physical, sensory, and cognitive abilities; learning capacity; memory issues; environmental factors; and accrued experience. Prospective patients may be further categorized into specific characteristics and need classes, as well as within various types of environments (Fischer, 2001). Working with the "persona" concept (LeRouge et al., 2013) throughout the UCD process could be of enormous help, since it allows designers to better grasp and effectively focus on user's needs, rather than on user's capabilities. Moreover, a mixed persona-scenario-goal (PSG) type of methodological design strategy (Aoyama, 2007) might be a worthwhile conceptual extension to be used with this type of VRbased HCI for cognitive healthcare.

\section{Design for usability through iteration}

"Design for usability," a concept originally described by Gould and Lewis (1983), was the basis of a very helpful standard: "ISO 13407:1999 - Human-centered design processes for interactive systems." The design approach contained therein was updated to "ISO 9241-210:2010" and later revised in 2015 (Preece et al., 2015). In it the UCD process is defined as: "an approach to interactive systems development that aims to make systems usable and useful by focusing on the users, their needs and requirements, and by applying human factors/ergonomics, and usability knowledge and techniques." (ISO 9241-210:2010).

Regarding the design of HCI for VR-based cognitive healthcare interventions, we have established four characteristic principles as fundamental features of UCD within this "design for usability" concept. They are:

i. The UCD process is founded on explicit understanding of the user, the tasks and the environment.

ii. Users (patients and caregivers) are involved throughout the entire UCD process.

iii. The UCD process is driven by usability optimization and is refined through user-centered evaluation.

iv. The UCD process is an iterative procedure.

On the basis of the above four characteristic principles we have defined three strategic procedural directions to be followed when applying UCD to HCI for VR-based cognitive healthcare interventions for ADRD (García-Betances, 2017). Specifically these central directions are:

a. Placing an early focus on patients and tasks: Understand, observe and study the patient and the nature of the tasks to be implemented, considering the patient's cognitive, behavioral, anthropomorphic and attitudinal characteristics.

b. Performing empirical assessments: Observe, record and analyze the patient's performance and reactions and usability issues, by means of scenarios or mock-ups in early design stages, and actual simulations and/or prototypes in later design iterations.

c. Utilizing iteration: Use an evolutionary type of design process contingent upon the patient's continuous feedback, within a series of "design, test, measurement, and redesign" iterative cycles. Identified usability problems are dealt with early and then retested to confirm the effect of any improvement.

In view of the above concepts and strategies, we suggest the following set of general design guidelines to optimize the 
usability of $\mathrm{HCI}$ in VR-based cognitive healthcare interventions:

1) Use both knowledge in the world and in the head: Provide clear instructions and user guides for the intervention, considering the patient's knowledge requirements.

2) Simplify tasks' structure: Make tasks simple throughout the intervention, so that the patient does not have to memorize or learn long chains of actions.

3) Maintain visibility: Fill any execution interruptions so that functionalities may be easily understood with as little additional information as possible.

4) Use familiar structures: Use common knowledge-based element placement within the graphic scenario.

5) Include natural and artificial constraints: Provide clear indications of what is or not possible to do during expected actions.

6) Design for error: Include mitigation protocols to amend foreseeable system errors and possible patient mistakes.

7) Standardize: Follow as much as possible commonly utilized standards whenever they might be applicable.

Operationally speaking, UCD methodology (Haklay and Nivala, 2010) may be divided into four distinct stages (described below) that advance within iterative optimization cycles. In the case of the design process for HCI of VR-based cognitive healthcare intervention the basic stages may be formulated as follows (García-Betances, 2017):

i. Analysis: Fully specify and understand the use context and clearly define patient requirements. Describe the characteristics of the potential patients, key users' needs, goals and constraints; the intended tasks, and organizational, technical and physical environment or context; the data that needs to be collect and how to analyze and interpret it.

ii. Design: Devise the HCI tools to be utilized, together with the specific intervention tasks to be performed by the patient to attain the intended outcomes. Generate means and protocols for patient feedback and data collection. Develop preliminary design muck-ups.

iii. Implementation: Assemble a working prototype ready for patient use and evaluation, and, if needed, produce several versions for side-by-side comparison.

iv. Evaluation: Perform sufficient user-based validation of the intervention, especially intervention effectiveness and usability issues (e.g., efficiency, satisfaction, memorability, encountered errors, etc.). Once this stage is completed, the cyclic process returns to the design stage for further iterative optimization until satisfactory results are achieved.

A schematic visual representation of typical activities and outputs of UCD is presented in Fig. 1, as suggested by the ISO 9241-210:2010 standard. As already mentioned, customizable design-for-the-goal type of UCD methodologies still have not been used much in the area of healthcare related technology, including applications intended for elderly people or for those cognitively impaired (LeRouge et al., 2013).

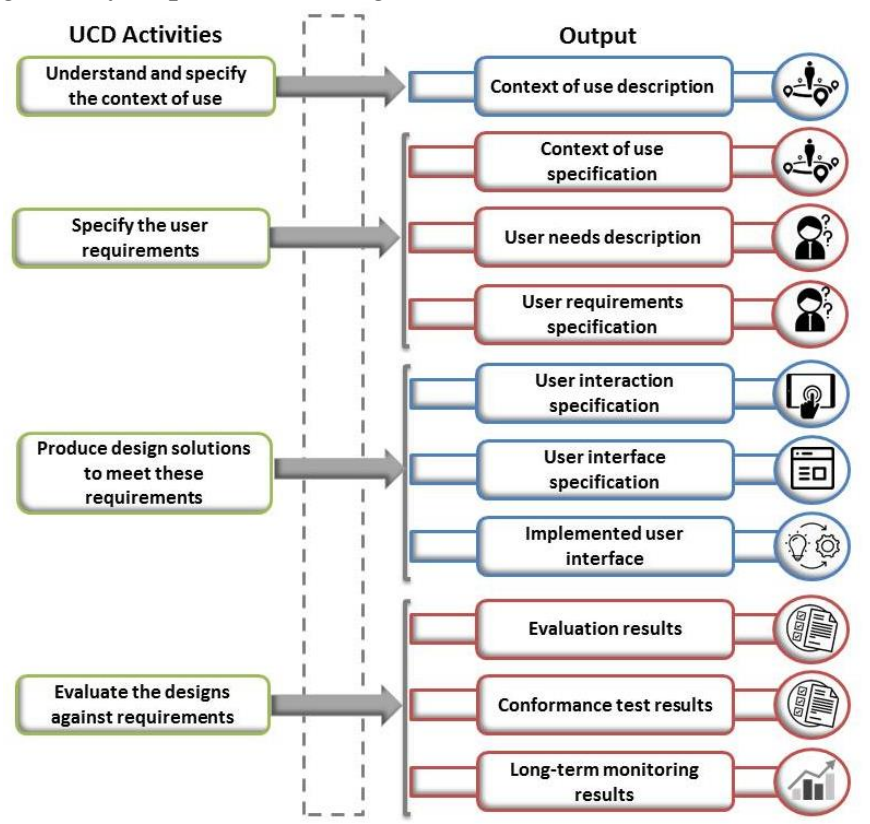

Fig. 1. Activities and outputs in user-centered design of the VR-based HCI (García-Betances, 2017). 


\section{Usability concerns: Patients' functional disabilities}

An old medically-oriented official study by the World Health Organization (WHO, 1980) provided some early guidance on special usability conditions derived from aging and functional impairment. A more recent publication, the International Classification of Functioning, Disability and Health (ICF) (WHO - ICF, 2001), suggests an interesting general framework to describe and quantify the impact of health issues and disabilities. ICF specifies a comprehensive classification of functional states associated with health that can be useful as a common reference for comparison using shared metrics. "In clinical settings ICF is used for functional status assessment, goal setting, treatment planning and monitoring, as well as outcome measurement" (WHO - ICF, 2001). ICF represents a valuable starting point to identify patients' disabilities and functioning conditions (Castillejo et al., 2014a; 2014b).

\subsection{Individualized Design Personalization}

Regarding ADRD, it is worthwhile to bear in mind that the manifestation of cognitive decline symptoms is not unique for all patients, even when they appear to be at similar stages of illness progression. Neuropathological changes caused by ADRD that occur in the human brain considerably differ from one patient to another. Moreover, each patient has particular personal circumstances, such as age, familial and social environments, economic position, educational level, physical health condition, and mental reserve level, among others. They all play important roles in the manifestation of functional disabilities and ensuing consequences. Therefore, the design of HCI in VR-based cognitive interventions for ADRD must be personalized in order to fully account for the specific functional disabilities that condition the performance of each individual patient. Gender considerations also must be included, because there exist gender-based differences in brain activity that might relate to risk factors that are characteristic of ADRD. Significant quantifiable differences between women's and men's brain activity have been observed at several regions of the brain using functional neuroimaging (Amen et al., 2017). Awareness of gender-specific differences could be important for proper VR-based cognitive healthcare intervention design and evaluation (Nebel, 2018).

\subsection{Addressing Accessibility Concerns}

We have found that a simple but expedient way to start to address HCI accessibility issues during the design of VR-based interventions for cognitive healthcare purposes is to initially utilize strategies similar to the already proven W3C's World Wide Web Consortium (W3C) Web accessibility guidelines for people with disabilities (García-Betances, 2017). We have been able to successfully adapt the W3C accessibility guidelines to UCD of VR-based cognitive interventions in those instances where they are in general suitable for this patient-centered design process.

\subsubsection{Cognitive Accessibility}

Accessibility problems specifically resulting from the patient's ADRD-derived cognitive disabilities must be the first concern to be addressed during the VR intervention's UCD process. Strategies that address this type of cognitive accessibility issues were adapted from the W3C Cognitive and Learning Disabilities Accessibility (COGA) guidelines (COGA, 2018). These guidelines are based on "Gap analyses" (CARGA, 2018) which have been specified by industry and university experts. In the present case, the identification and analysis of the accessibility gaps of the VR-based cognitive healthcare intervention ought to include at least the following aspects:

- Background study of ADRD, including an extensive review of past research about the cognitive disabilities of ADRD patients, as well as the ensuing challenges posed to the HCI by each of them (CAUR, 2018).

- Identify and address logging in, security and safety issues of the VR platform that are particularly affected by the presence of ADRD cognitive disabilities (CAIP, 2018); and

- Appropriate use of Authoring techniques (COGA, 2018).

Table II summarizes our recommended guidelines to avoid or minimize ADRD-related cognitive accessibility issues of VRbased cognitive healthcare interventions. The table indicates the related HCI usability strategies to be implemented during the design process of VR-based neurocognitive interventions for ADRD.

\subsubsection{Physical Accessibility}

Accessibility issues directly originated by ADRD patients' physical disabilities also must be addressed during the UCD process, especially those related to the HCI (García-Betances, 2017). As explained before, these issues may be initially confronted following guidelines similar to those of WCAG 2.0 conformance levels (WCAG, 2008). Conformance levels may be determined by assessing the increasing severity of the physical disability, following W3C criteria for A, AA, and AAA levels. Other accessibility issues resulting from physical disabilities that might indirectly arise from either the patient's cognitive disabilities, or from other co-morbidities, may be initially addressed using analogous guidelines.

Table III presents principles, recommended guidelines and corresponding purposes, pertaining to physical disability-related accessibility issues, as adapted from general WCAG guidelines, to be used during the design of VR-based cognitive healthcare intervention for ADRD. 
TABLE II

RECOMMENDED GUIDELINES TO ADDRESS COGNITIVE DISABILITIES-

RELATED HCI ACCESSIBILITY ISSUES IN THE DESIGN OF VR COGNITIVE HEALTHCARE INTERVENTIONS (García-Betances, 2017).

\begin{tabular}{|c|c|}
\hline Technique & HCl usability strategy \\
\hline $\begin{array}{c}\text { Clear } \\
\text { structure }\end{array}$ & $\begin{array}{l}\checkmark \text { Include only a few main tasks to be performed by the patient; } \\
\checkmark \text { Use a single topic, idea, or short sentence: Time each event } \\
\quad \text { carefully; } \\
\checkmark \text { Allow for personalization: Content should be individually } \\
\quad \text { adaptable to each patient and dynamically reconfigurable; } \\
\checkmark \text { Provide patients with easy to understand information; } \\
\checkmark \text { Portray clear \& easily understandable graphic environments; }\end{array}$ \\
\hline $\begin{array}{c}\text { Adequate } \\
\text { Style }\end{array}$ & $\begin{array}{l}\checkmark \text { Provide short \& clear indications to the patient; } \\
\checkmark \text { Explain what outcomes to expect; } \\
\checkmark \text { Avoid complicated visual metaphors; } \\
\checkmark \text { Use commonly used and well-known graphic symbols; } \\
\checkmark \text { Use simple movements; }\end{array}$ \\
\hline Feedback & $\checkmark$ Provide direct monitoring and rapid sensorial feedback; \\
\hline $\begin{array}{l}\text { Help \& } \\
\text { support }\end{array}$ & $\begin{array}{l}\checkmark \text { Provide short infographic tips; } \\
\checkmark \text { Use graphics to reinforce important issues; } \\
\checkmark \text { Use default formats (e.g. temperature, time, currency; etc.); } \\
\checkmark \text { Reinforce patient understanding with graphics or symbols; } \\
\checkmark \text { If possible, provide speech support; }\end{array}$ \\
\hline $\begin{array}{l}\text { Clear } \\
\text { design }\end{array}$ & $\begin{array}{l}\checkmark \text { Use clearly identifiable visual style for items that are actionable; } \\
\checkmark \text { Avoid difficult to see details; } \\
\checkmark \text { Highlight key issues: Place important features up front; }\end{array}$ \\
\hline $\begin{array}{l}\text { Complete } \\
\text { and check }\end{array}$ & $\begin{array}{l}\checkmark \text { Prevent errors: Error correction should be transparent to patient; } \\
\checkmark \text { Promote patient attention \& focus: avoid distractions \& } \\
\text { interruptions; } \\
\checkmark \text { Allow for iterative desian refinement }\end{array}$ \\
\hline
\end{tabular}

TABLE III

RECOMMENDED GUIDELINES TO ADDRESS PHYSICAL DisABILITIES-RELATED HCI ACCESSIBILITY ISSUES IN THE DESIGN OF VR COGNITIVE HEALTHCARE INTERVENTIONS FOR ADRD (García-Betances, 2017).

\begin{tabular}{|c|c|c|}
\hline Principles & Guidelines & Purposes \\
\hline \multirow{4}{*}{$\begin{array}{l}\text { Perceivable: } \\
\text { Information and } \\
\text { patient } \\
\text { interface must } \\
\text { be easily } \\
\text { observed and } \\
\text { recognized }\end{array}$} & $\begin{array}{l}\text { Provide alternatives for content so that it can be } \\
\text { changed into other forms according to patient's } \\
\text { special needs. }\end{array}$ & $\begin{array}{l}\text { Content that best circumvents patient disability (e.g. enlarged } \\
\text { scenario, louder sound, different sensory forms). }\end{array}$ \\
\hline & Provide alternatives for time-based media. & $\begin{array}{l}\text { Access time-based and synchronized media. (e.g. audio, video, } \\
\text { another sense, and combinations) }\end{array}$ \\
\hline & $\begin{array}{l}\text { Create content that can be presented in different } \\
\text { ways without losing information or structure. }\end{array}$ & $\begin{array}{l}\text { Ensure that all information is available in a form that can be } \\
\text { perceived by all users. }\end{array}$ \\
\hline & $\begin{array}{l}\text { Make it easier for patients to see and hear content } \\
\text { including separating foreground from background. }\end{array}$ & $\begin{array}{l}\text { Default presentation as easy to perceive as possible to patients } \\
\text { with physical disabilities. }\end{array}$ \\
\hline \multirow{4}{*}{\begin{tabular}{l}
\multicolumn{1}{c}{ Operable: } \\
Interface \\
should not \\
require \\
interactions \\
that patient \\
cannot perform
\end{tabular}} & $\begin{array}{l}\text { Make all functionalities available regardless of } \\
\text { patient's physical disability }\end{array}$ & $\begin{array}{l}\text { Interface through speech input, or any other kind of assistive } \\
\text { technologies that can produce an output. }\end{array}$ \\
\hline & Provide patients enough time to find content. & Ensure completion of tasks at user's own pace. \\
\hline & $\begin{array}{l}\text { Do not include content known to cause seizures or } \\
\text { motion sickness. }\end{array}$ & $\begin{array}{l}\text { Avoid the types of flashes that are most likely to cause seizure } \\
\text { when viewed even for a brief time. }\end{array}$ \\
\hline & $\begin{array}{l}\text { Provide ways to help patients navigate, find content, } \\
\text { and determine where they are. }\end{array}$ & $\begin{array}{l}\text { Facilitate patients' navigation and orientation and allow them to } \\
\text { keep track of their location. }\end{array}$ \\
\hline \multirow{3}{*}{$\begin{array}{l}\text { Understandable } \\
\text { Content and } \\
\text { operation of } \\
\text { interface } \\
\text { cannot be } \\
\text { beyond user } \\
\text { understanding } \\
\end{array}$} & Make graphics highly visible and understandable. & Allow graphic content to be seen with assistive technologies. \\
\hline & Make content appear and operate predictably. & $\begin{array}{l}\text { Present content in predictable order by making the behavior of } \\
\text { functional and interactive components predictable. }\end{array}$ \\
\hline & Help patients avoid and correct own mistakes. & $\begin{array}{l}\text { Reduce the number of errors that can be made, increase } \\
\text { likelihood that errors will be noticed by patients, and help them } \\
\text { understand how to correct an error. }\end{array}$ \\
\hline $\begin{array}{l}\text { Robust: } \\
\text { should be } \\
\text { readily } \\
\text { accessible }\end{array}$ & $\begin{array}{l}\text { Provide compatibility support for current, emerging } \\
\text { and future user assistive technologies. }\end{array}$ & Allow patient's use of assistive technologies. \\
\hline
\end{tabular}

\section{A design framework}

Based on the above premises and considering the present state of affairs regarding the field of cognitive training interventions in general, we propose a methodological design framework to help the development and design of future VR-based cognitive healthcare intervention for people with ADRD (García-Betances, 2017).

The design framework is meant to shed light on important specific requirements and functionalities needed to enrich the design process of VR-based cognitive interventions. Some of the most significant required requirements and functionalities are: 
- Systematic frame of reference to assist in design conceptualization and definition of the intended goals and the required specifications;

- Roadmap to clearly guide through the different stages of the entire design process on the basis of standardized references;

- Effective coordination to integrate complex interactions between diverse elements and disciplines that belong to different knowledge domains (cognitive neuroscience, medical health care, computer technology, information systems, electronics engineering, software development, etc.)

- Organization of flexible customization of diverse components to be able to adapt them to different user needs;

- Anticipation of potential conflicts between initial design specifications, to facilitate early resolution;

- FORMULATION OF EVALUATION MEANS AND MEASURES FOR COMPREHENSIVE AND RELIABLE ASSESSMENT OF THE DESIGN;

- ITERATIVE CORRECTION OF DEFICIENCIES THAT MAY BE UNCOVERED AT LATE STAGES, DURING TESTING OR EVEN ACTUAL USE;

- DESIGN OPTIMIZATION CAPACITY THROUGH REGULAR REVISION.

The framework also helps to define and specify the chief desirable expectations, concerns and considerations to be addressed during the VR-based cognitive intervention design process. We have grouped them into five main categories (García-Betances, 2017), as summarized in the chart shown in Fig. 2.

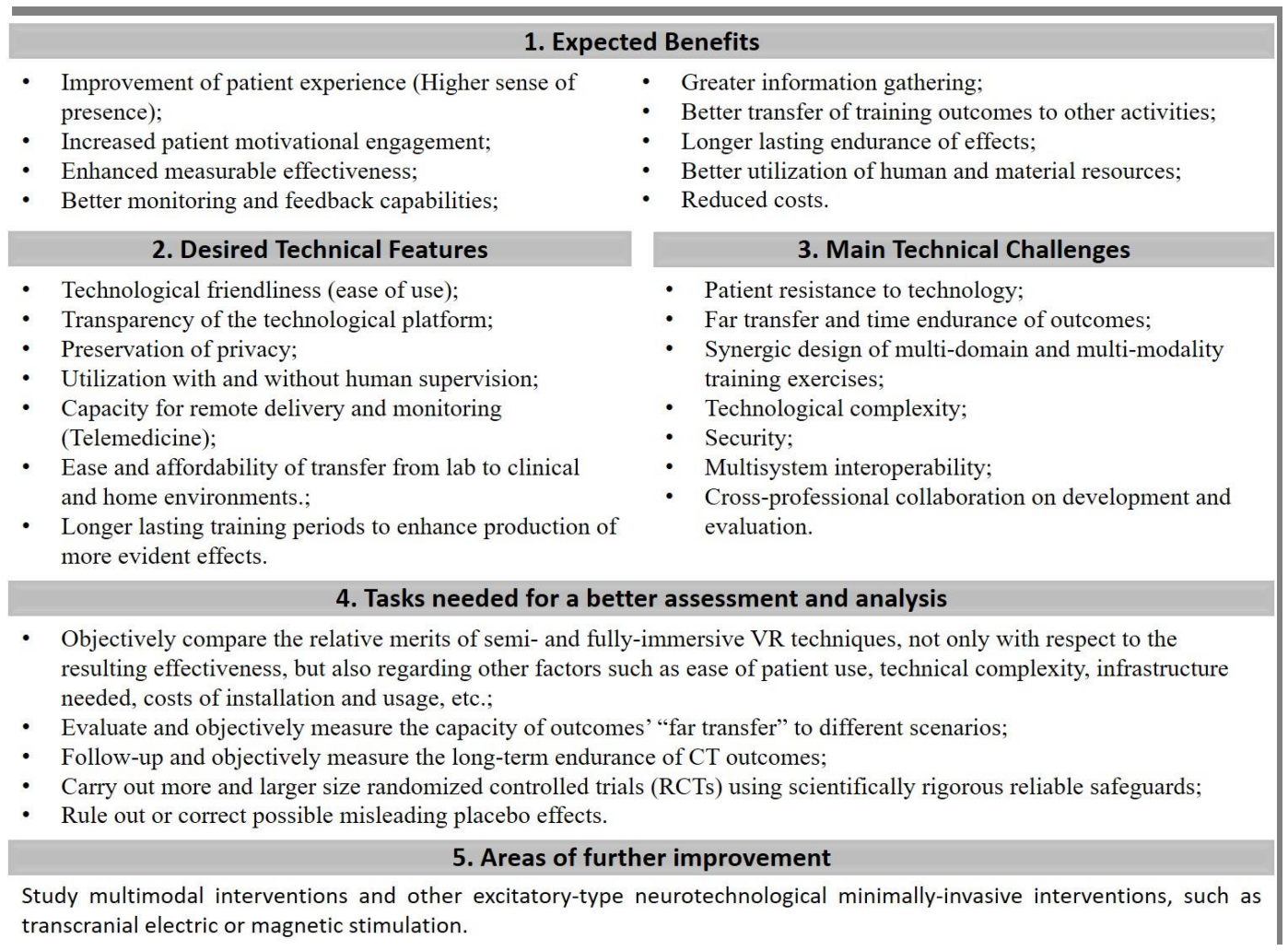

Fig. 2. Principal desirable expectations, concerns and considerations of a VR-based cognitive intervention design (García-Betances, 2017).

\section{Design phases}

For descriptive purposes the proposed framework may be divided into the three major design phases, as indicated in Fig. 3. The components related to each of the framework phases are labeled by two colors in Fig. 3: The basic components (green boxes in Fig. 3) comprise the target group, purpose, research questions/variables, and context factors; and the evaluation components (blue boxes in Fig. 3) comprise the previous knowledge and the data collection and evaluation components. 


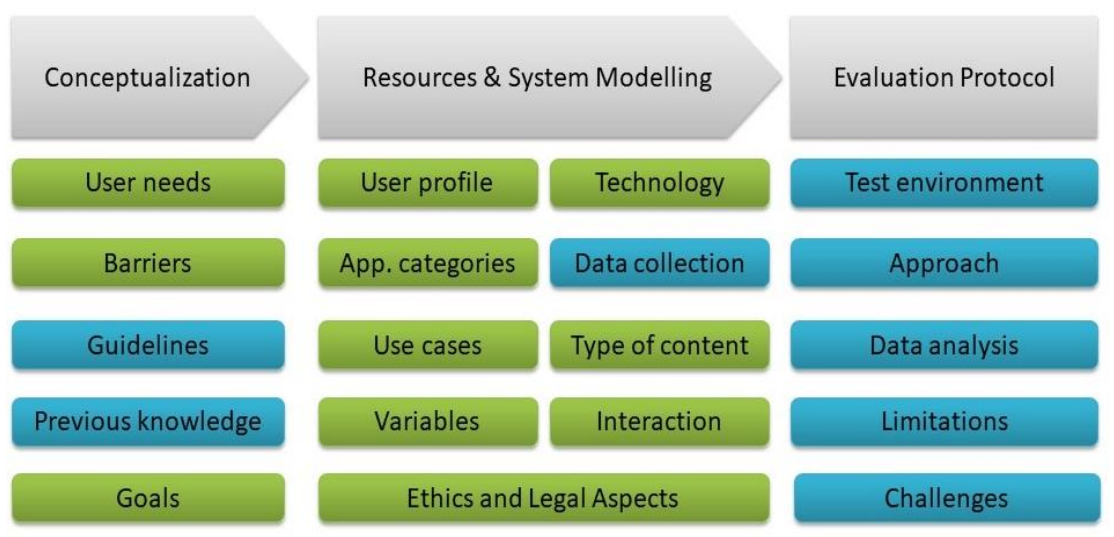

Fig. 3. Major design process phases (García-Betances, 2017).

\subsection{Conceptualization phase}

This first phase includes the components related to the specific problems to be addressed, such as: barriers, goals, user needs and characteristics that will help in the definition of the user profile and the usage cases. This phase also comprises the analysis of previous specific knowledge, general know-how and the most common existing guidelines, all in order to ensure that the design, developments and evaluations are done following a truly evidence-based approach.

An important aspect to bear in mind when dealing with people affected by ADRD is the presence of comorbidities: physiological processes related to aging (e.g. presbyopia, osteoarthritic, decreased agility and responsiveness reflex, etc.) as well as those that arise from the neurodegenerative disease itself (Monteagudo, 2012). These issues interfere with the acceptance of technology, as well as with the user's interaction capacity. Therefore, usability and accessibility criteria should be included early in the design process to produce friendly, easy-to-use, safe and intuitive applications.

Even if cognitive and functional impairments have not yet been fully manifested during the early stages of AD, e.g. in MCI, their emerging presence is a real possibility. Thus, they must be considered during the design (Rodakowski et al., 2018). Incipient memory deficits, difficulties in planning or solving problems, disorientation, difficulties understanding visual images and spatial relationships, problems with writing and speaking, misplacing things, poor judgement, changes in mood and personality, etc., might all be tale telling symptoms (Alzheimer's Association, 2018).

Unfortunately deficits in memory and communication skills, produced by the cognitive disability, will complicate the use of VR-based platforms. For example, alteration of episodic memory can significantly affect the verbal and visual capacity of people with ADRD, even though other types of memory, such as semantic and procedural memory, might be still preserved during the initial phases of AD (NIA, 2018).

It is commonly believed by many that older people, even when healthy, will in general experience considerable difficulties when using new ICT, and thus, their poor acceptance is assumed (Ma et al., 2015). However, the categorical nature of this stereotype has been questioned. A recent large meta-analysis about the relationship between chronological age and technology acceptance (Hauk et al., 2018) suggests that age-related negative perception of new ICT is modulated by the technology type, in the sense that negative perception is more intense when the technology fails to be perceived by the older users as intended to directly address their needs. Unfortunately, there are not many systematic studies that look directly into technological acceptance issues by people with ADRD. Still, age-awareness must be included within any UCD methodology that intends to deal with VRbased technology acceptance issues of older people with ADRD.

\subsection{Resources and System Implementation phase}

This second phase of design process refers to system components configuration associated with the definition of its actual resources, as pertaining to the following specific aspects:

- Concepts: define user profiles, usage cases, and variables;

- Application category: intended purpose (impairment assessment, diagnosis, cognitive training or activation for

possible cognitive function improvement; symptom mitigation, behavioral remediation, etc.)

- Types of sensory content: HClinterface (e.g. visual, audio, kinetic, haptic, olfactory, etc.);

- Technological: specific VR platform technology to be used, other HCI devices, types of data collection needs and technical means, processing and analysis methodology, security, mechanisms for patient interactivity, security and safety precautions and protection;

- Ethics and legal aspects: foresee all that might be involved in the design and later use of the intervention.

Design efforts nowadays are incorporating new paradigms into their repertoire of service personalization tools, in response to specific users' self-customization needs. These new paradigms embrace the perspective of inclusive and universal design concepts to satisfy the needs of specifically typified groups of users, such as the elderly, or people with physical or mental disabilities, and any combination thereof. The use of inclusive universal design techniques and tools adjustable to particular situations can yield solutions that adequately serve the needs of persons with disabilities (Hendriks, 2007). 
Some of the problems faced in the design of applications for persons with disabilities are related to usability issues, such as: functional limitations, behavioral and cognitive limitations, reduced capabilities, etc., which could strongly influence user acceptance (Eberle et al., 2011). Both the elderly and cognitively impaired people have needs and concerns different from those of general users, not only on account of their particular cognitive impairments, but also from aging, or pre-existing physical disabilities and other comorbidities. Unfortunately, such special needs and concerns are easy to be underestimated, misrepresented or even sometimes ignored during development and design. Therefore, it is should be kept in mind at all times that the circumstances, conditions and abilities of cognitively impaired users differ considerably from those of general users. And that the acceptance and usability problems that arise from those differences must be directly dealt with during the design process so that the resulting application is not only acceptable but also usable by them.

There have been various efforts to overcome several of the technological barriers faced by users affected by specific impairments or limitations, that take into account their particular characteristics and needs (Newell and Gregor, 1997; Alm and Nakamura, 2001; Gregor et al., 2002; Eisapour et al., 2018). Fischer (2001) classified users into different types, with respect to particular needs and characteristics, and within various environments. But a classification of users merely according to their expertise and knowledge (e.g., novel, intermediate, and expert) is often not enough. Gregor et al. (2002) analyzed the particular issues involved in the design process of ICT solutions specifically aimed at elderly users. Some of the relevant abilities to be considered during the design process were identified, such as: physical, sensory, and cognitive abilities; learning capacity; memory problems; environmental factors; and accumulated experience (Gregor et al., 2002).

Motivational deficits are also present in many patients with ADRD. They must be taken into serious consideration from the start of design, because maintaining high levels of motivation and engagement are essential conditions for the success of any intervention. It has been suggested that stimulating affect and emotion in the user might help motivate acceptance and promote usability (Robillard and Hoey, 2018), provoking greater engagement and perhaps even improved effectiveness of neurocognitive assistive care technology. If this reasonable supposition turns out to be true, it implies that it would be advantageous to include strategies of affective and persuasive computing (García-Betances et al, 2015c) into the design cycle of VR-based applications for neurocognitive assistive care of older people with ADRD.

The use of immersive 3D VR technology itself already enhances engagement (García-Betances, 2017). There are additional strategies to promote engagement, e.g. making the neurocognitive assistive care intervention in the form of a recreational experience (Hodge et al, 2018). Recreation in general promotes motivation and translates into significant improvement of engagement. Gamification, an overt form of entertainment, can be a very useful tool for neurocognitive intervention in helping to maintain interest and to minimize or disguise boring activities by providing recreational enjoyment. Gamification has been used and continues to be used in many of the commercially available brain training products (García-Betances et al., 2018). A recent example of gamification is a novel memory training game based on the iPad® platform that is said to produce improvements in the episodic memory of patients with amnesic MCI (aMCI) (Savulich et al., 2017).

Ethical and legal considerations should always be present when designing, implementing and assessing interventions. The potential of technology use in healthcare to cause dehumanization of the patient must be not be underestimated. Therefore, this risk must be prevented or minimized during the design and implementation of VR-based cognitive healthcare intervention. Designers should exercise empathy during all phases of design, keeping in mind that patients should maintain their dignity while engaged with the healthcare intervention (Hosking et al., 2015). Other impotant ethical issues that should be inevitably addressed are: (1) data protection and security; (2) data confidentiality; (3) information property; (4) authenticity, accuracy and fidelity of information; (5), informed consent of participants (for the evaluation phase).

The EU commission has a set of guidelines to address identification issues, directions and major concepts of data protection and privacy (European Data Protection Supervisor, 2018). Similarly, the American Psychological Association has published a set of guidelines for the evaluation of dementia and age-related cognitive change. This guide can become a very useful instrument when designing solutions for following-up ADRD evolution (APA, 2012).

The use of VR technology adds additional ethical concerns when involving vulnerable population groups (e.g. impaired awareness, psychiatric patients, etc.). Particular threats inherent to VR exposure, such as cyber-sickness, should be given special consideration (Rizzo et al., 2002). Screening procedures should be used to identify possible side effects of VR (Kim et al., 2018) in order to consider design additions to minimize risks.

\subsection{Evaluation phase}

The final phase requires to specify an evaluation approach to assess the VR-based neurocognitive intervention design. This includes the definition of a test environment, a data analysis methodology, and the identification of the limitations of the study. These factors impose new burdens and challenges to the design.

Assessment of VR-based neurocognitive intervention designs must not be handled as a mere technical evaluation. Such a narrow-view would render it mostly irrelevant, as it would ignore the central intended purpose of the intervention, which is to produce a significant health benefit. Moreover, no statistical analysis of experimental results can be better than the original design of the study that generated the ensuing data. Analogously, no ICT-based cognitive healthcare intervention design can be better than the underlying phenomenological understanding (the theory) of the health issue it tries to address (Fiedler, 2017).

A logical way to assess VR-based cognitive healthcare intervention design is to follow approaches similar to those used to evaluate health information systems in general (Andargoli et al., 2017 ). An integrative type of approach that will cover all aspects of the intervention should be preferred. A complete evaluation framework like the "content, context and process (CCP)" 
type suggested by Stockdale and Standing (2006) is an appropriate robust alternative. Such an integral evaluation of the intervention design proceeds in an interpretive manner, guided by three fundamental premises: 1. context ('who' and 'why'); 2. content ('what'); and 3. process ('how' and 'when'). Evaluation of performance and effectiveness should be complemented by semi-structured interviews of designers, including their own formal evaluation (Song and Sakao, 2017).

Whenever a test is to be conducted with real users for evaluating a VR neurocognitive intervention design, the standard procedure is, as in any ICT-based healthcare intervention, to conduct randomized controlled trials (RCT). The RCT procedures must be well designed, appropriately and rigorously conducted to avoid meaningless, wrong or biased outcomes; and should be clearly reported in an easy-to-follow manner, providing all the information needed for easy replication of the trial.

These types of concerns regarding reporting of RCTs have been formally addressed by the "CONsolidated Standards Of Reporting Trials" (CONSORT, 2010a), a group that comprises experts in clinical trial methodology, guideline development, biomedical journal editors, and research funders. CONSORT's statement for improving the reporting quality of RCTs (Schulz et al., 2010). Based on the CONSORT group methodological guidelines, we put forward some basic recommendations for trial evaluation of VR-based neurocognitive assistive care intervention designs (García-Betances, 2017):

- Eligibility criteria: (a) Define eligible participants by the nature and level of the cognitive disability in question;

(b) exclude persons thought to be especially vulnerable to harm from the intervention.

- Control groups: Include both active (fake intervention) and passive (no intervention).

- Randomization: Assign participants to each comparison group using an unpredictable random process.

- Contextual circumstances: (a) Identify and describe where participants will be recruited, their social, economic, and cultural environment, etc. and (b) Describe the settings and locations where data will be collected.

- Sample size: Establish criterion and methods for calculation.

- Ethics: Strictly adhere to accepted ethical principles and practices for ADRD (Davis, 2017), following usual pertinent legal normative, such as obtaining proper informed consent, keeping data security and privacy, etc.

A full list of recommendations for design, conduction and reporting of RCT can be found at the CONSORT group Website (CONSORT, 2010a; Schulz et al., 2010). The advance of participants through the enrollment, allocation, follow-up and analysis phases of the RCT may be conveniently tracked using the flow diagram template provided by the CONSORT Group (CONSORT, 2019b).

The ongoing debate about the effectiveness of commercial brain training products (García-Betances et al., 2018) still demands to fully demonstrate and validate beyond any doubt whether there can be actual skill transference from cognitive training to reallife tasks, and, if any, what the persistence in time of such transference would be. A consensus report of the Committee on the Public Health Dimension of Cognitive Aging of the US Academy of Medicine recommends using certain specific criteria to evaluate the effectiveness of cognitive training programs (Blazer et al., 2015). Those criteria, once they are translated into guidelines to assess the occurrence of "far transfer" in VR-based neurocognitive interventions, may be summed up into three activities: (a) Determine whether the trained skills are retained, and, if so, how much and for how long; (b) Ascertain whether trained task skills transfer has happened to other tasks that are founded on the same cognitive constructs as the originally trained task; (c) Establish whether trained task skills transfer has happened to skills that are relevant to real ADL. As a final confirmation of unquestionable effectiveness of the cognitive intervention, the assessment of the results ought to be independently confirmed by other trustworthy research groups and reliable controlled clinical trials.

\section{Functional schematic framework}

The proposed methodological design framework for VR-based cognitive healthcare interventions for ADRD consists of three main phases: (1) Conceptualization; (2) Resources \& system implementation; and (3) Evaluation. These phases are complemented by other important components that significantly affect the development, design and testing processes. The components are those aspects that are closely related to: (a) User's particular needs regarding comprehensibility, accessibility, usability, safety, etc. (b) The specific type of VR technology to be used. (c) The HCI techniques involved. (d) Privacy and data security concerns. (e) Ethical safeguards, dignity concerns, and pertinent legal issues.

Fig. 3 shows the schematic diagram of the proposed functional framework (García-Betances, 2017). It is presented in a schematic type of view, adapted to the design case at hand from Latham's (2014) schematic representation. The interrelations between the modules and components of the framework, shown as bidirectional arrows, are indicative of this design process' completely adaptive nature, from problem conception to the final intervention product. 


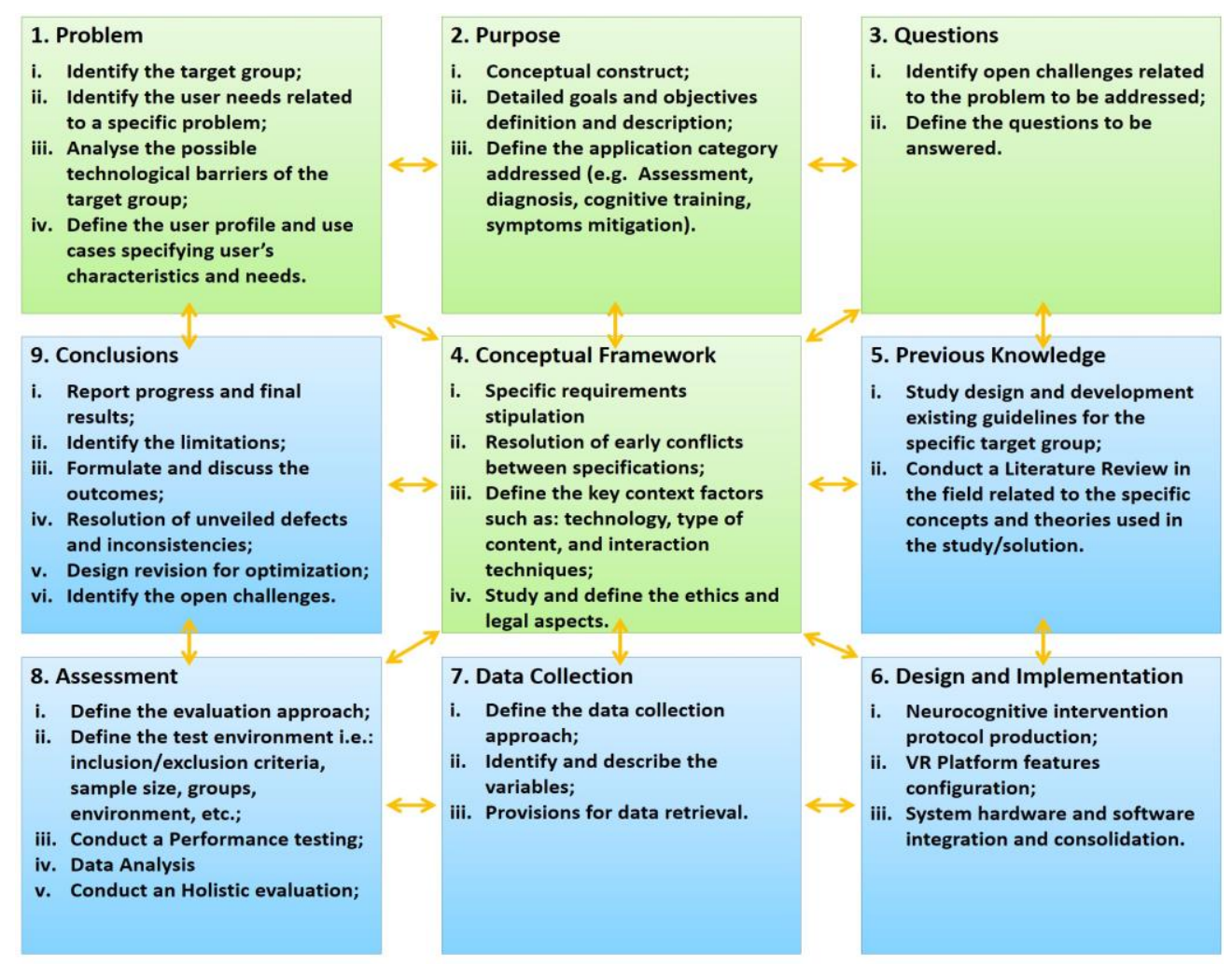

Fig. 3. Functional schematic view of the methodological design framework (García-Betances, 2017).

The top three modules, shown in green color in Fig. 3 graphically forming a letter "T," correspond to the conceptualization phase, while the five others, shown in blue color forming a letter "U" at the bottom, correspond to the two remaining phases: resources and system implementation, and evaluation. The dynamic interconnection of components to their neighbors also meant to indicate the progressive refinement capability and adaptability of the design process, based on continuous outcome evaluation and user's feedback, better illustrated in a following roadmap.

\section{A roadmap}

The design framework is depicted again in Fig. 4, now in the form of a roadmap, or flow diagram, comprised of the three main phases. The red dashed square encloses the components related to the conceptualization and implementation phases. The relationships between the components indicate the flow of activities. Once the intervention has been implemented, the evaluation stage starts by defining the evaluation approach on the basis of the stated goals, objectives and predefined requirements, followed by data acquisition and analysis. Performance testing and holistic evaluation follows. Once the outcomes have been analyzed and the evaluation has been completed, a methodological feedback route is provided to the two first stages' components to accomplish the iterative optimization refinement of the VR cognitive healthcare intervention design. 


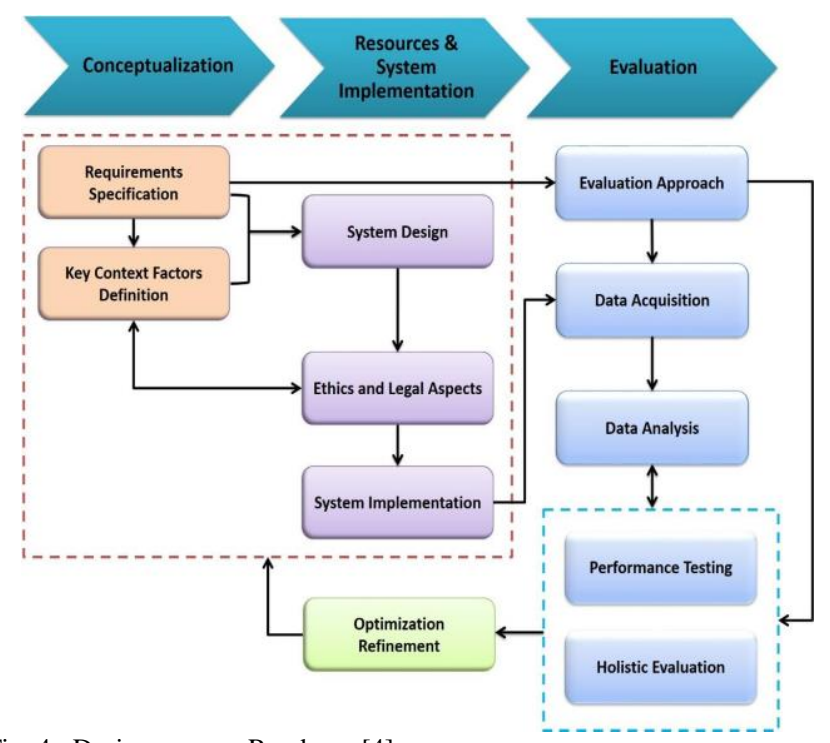

Fig. 4. Design process Roadmap [4].

\section{Conclusions}

We have argued that a resolute use of modern VR technology would provide an effective HCI that could significantly contribute to enhance the ultimate efficacy of computer-based cognitive healthcare interventions. We have shown that the design of VR-based cognitive healthcare interventions aimed in particular at ADRD patients imposes very strict specific requirements, additional to those others that are common to most types of VR application, that seriously challenge the design process. Results of a systematic SWOT analysis about the use of VR-based cognitive healthcare interventions for ADRD provided us some useful conceptual positions from which we then translated known specific requirements of ADRD patients into very concrete design strategies and guidelines, which are best executed using a patient-centered point of view.

To that end, we defined a methodological UCD framework for VR-based cognitive healthcare interventions for ADRD patients, based on a thorough examination of the available experience and on the soundest evidence on the subject (GarcíaBetances, 2017). The recommended guidelines and proposed framework could serve as useful methodological steering aid to coordinate multidisciplinary design processes of non-pharmacological interventions, intended to improve the effectiveness of cognitive healthcare for ADRD through the use of modern state-of-the-art VR technologies. Tackling the mentioned specific design's critical issues is essential to be able to improve the effectiveness of cognitive healthcare interventions through the use of VR technology. More effective cognitive healthcare interventions would undoubtedly help to enhance ADRD patients' daily living functional autonomy and thus their overall quality of life, as well as that of their caregivers. Such enhancement would have an extraordinary medical and social impact, as it would significantly contribute to easing the high personal, familial and societal burdens posed by the worldwide incidence of ADRD.

\section{Acknowledgements}

The development of this design framework was made possible thanks to the experience and knowledge base on ICTs for healthcare support of people living with disabilities, accumulated over the years at the Life Supporting Technologies (LifeSTech) Group (https://www.lst.tfo.upm.es) of the Higher Technical School of Telecommunications Engineers in Madrid's Polytechnic University (UPM), to whose past and present academic and administrative staff and students the authors are sincerely grateful. This work was carried out with the support of a Doctoral scholarship from UPM.

\section{References}

Ahmed, B., Kim, D.H., Hwang, Y. and Park, S.J., 2018, June. Treatment of Alzheimer's, Cognitive, Chronic Pain Rehabilitation, Depression and Anxiety disorders in One System for Elderly Using VR. In 2018 15th IEEE Int. Conf. on Ubiquitous Robots (UR), 26-30 June 2018, Honolulu, HI, USA. pp. 483-488. https://doi.org/10.1109/URAI.2018.8441897

Alm, N., Nakamura, K. 2001. Designing for ordinary and extraordinary users. ACM SIGCAPH Comp. and the Phys. Handicapped 69, $2-3$. https://doi.org/10.1145/569320.569321

Allaire, J.C., et al., 2014. A consensus on the brain training industry from the scientific community. Max Planck Institute for Human Development and Stanford Center on Longevity. http://longevity3.stanford.edu/blog/2014/10/15/the-consensus-on-the-brain-trainingindustry-from-the-scientific-community-2/ (Accessed on 14 Sep. 2018)

Alzheimer's Association, 2018 Alzheimer's disease facts and figures. Alzheimer's \& Dementia: The J. of the Alzheimer's Assoc. 14 (3), $367-$ 429. https://doi.org/10.1016/j.jalz.2018.02.001 
Amen, D.G., Trujillo, M., Keator, D., Taylor, D.V., Willeumier, K., Meysami, S., Raji, C.A., 2017. Gender-Based Cerebral Perfusion Differences in 46,034 Functional Neuroimaging Scans. J. Alzheimer's Disease 60 (2), 605-614. https://doi.org/10.3233/JAD-170432

Andargoli, A.E., Scheepers, H., Rajendran, D., Sohal, A., 2017. Health information systems evaluation frameworks: A systematic review. Int. J. of Medical Informatics 97, 195-209. https://doi.org/10.1016/j.ijmedinf.2016.10.008

Aoyama, M., 2007. Persona-Scenario-Goal Methodology for User-Centered Requirements Engineering. In: Proc. 15th IEEE Int. Requirements Engineering Conf., Delhi, India, Oct 2007, pp. 307-312. https://doi.org/10.1109/RE.2007.50

APA, 2012. American Psychological Association Guidelines for the evaluation of dementia and age-related cognitive change. The American psychologist 67(1), 1-9. https://doi.org/10.1037/a0024643

Blazer, D.G., Yaffe, K., Liverman, C.T., 2015. Cognitive Aging: Progress in Understanding and Opportunities for Action - Consensus Study Report, The National Academies Press. Washington, D.C., USA. https://doi.org/10.17226/21693

Caggianese, G., Chirico, A., De Pietro, G., Gallo, L., Giordano, A., Predazzi, M. Neroni, P., 2018. Towards a Virtual Reality Cognitive Training System for Mild Cognitive Impairment and Alzheimer's Disease Patients. In: 32nd IEEE Int. Conf. on Adv. Info. Networking and App. Workshops (WAINA), 16-18 May 2018, Krakow, Poland. pp. 663-667. https://doi.org/10.1109/WAINA.2018.00164

CAIP, 2018. Cognitive Accessibility Issue Papers. W3C Editor's Draft 13 September 2018. https://rawgit.com/w3c/coga/master/issue-papers/ (accessed 14 Sep. 2018)

CARGA, 2018. Cognitive Accessibility Roadmap and Gap Analysis. W3C Working Draft 13 September 2018. https://rawgit.com/w3c/coga/master/gap-analysis/ (accessed 14 Sep. 2018)

Carrión, C., Folkvord, F., Anastasiadou, D. Aymerich, M., 2018. Cognitive therapy for dementia patients: A systematic review. Dementia and geriatric cognitive disorders, 46(1-2), 1-26. https://doi.org/10.1159/000490851

Casas, R., Blasco Marín, R. Robinet, A., Roy Delgado, A., Roy Yarza, A., McGinn, J., 2008. User Modelling in Ambient Intelligence for Elderly and Disabled People. Lecture Notes in Comp. Sci. 5105, 114-122. https://doi.org/10.1007/978-3-540-70540-6_15

Castillejo, E., Almeida, A., López-de-Ipiña, D., Chen, L., 2014b. Modeling users, context and devices for Ambient Assisted Living Environments. Sensors 14(3), 5354-5391. https://doi.org/10.3390/s140305354

Castillejo, E., Almeida, A., López-de-Ipiña, D., 2014a. Modelling users, context and devices for adaptive user interface systems. Int. J. Pervasive Computing and Comm. 10 (1), 69-91. https://doi.org/10.1108/IJPCC-09-2013-0028

CAUR, 2018. Cognitive Accessibility User Research, W3C Editor's Draft 22 August 2018. https://w3c.github.io/coga/user-research/ (accessed 14 Sep. 2018)

Chalfont, G., Milligan, C. Simpson, J., 2018. A mixed methods systematic review of multimodal non-pharmacological interventions to improve cognition for people with dementia. Dementia, p.1471301218795289. https://doi.org/10.1177/1471301218795289

Chang, Y.J., Liu, H.H., Kang, Y.S., Kao, C.C. Chang, Y.S., 2016. Using augmented reality smart glasses to design games for cognitive training. In: 13th IEEE Int. Conf. on Remote Eng. and Virtual Instr. (REV), 24-26 Feb. 2016, Madrid, Spain, pp. $252-253$. https://doi.org/10.1109/REV.2016.7444474

COGA, 2018. Techniques for the Cognitive and Learning Disabilities Accessibility Task Force (COGA), W3C Editor's Draft 13 September 2018. https://rawgit.com/w3c/coga/master/techniques/index.html (accessed 14 Sep. 2018)

CONSORT, 2010a. CONsolidated Standards Of Reporting Trials, CONSORT Group, http://www.consort-statement.org/about-consort (accessed 14 Sep. 2018)

CONSORT, 2010b. Transparent Reporting of Trials, CONSORT 2010 Flow Diagram, the CONSORT Group, http://www.consortstatement.org/download/Media/Default/Downloads/CONSORT\%202010\%20Flow\%20Diagram.doc

Coogan, C.G. He, B., 2018. Brain-computer interface control in a virtual reality environment and applications for the internet of things. IEEE Access, 6, 10840-10849. https://doi.org/10.1109/ACCESS.2018.2809453

da Costa, R.Q.M., Pompeu, J.E., de Mello, D.D., Moretto, E., Rodrigues, F.Z., dos Santos, M.D., Nitrini, R., Morganti, F., Brucki, S.M.D., 2018. Two new virtual reality tasks for the assessment of spatial orientation. Preliminary results of tolerability, sense of presence and usability. Dementia \& Neuropsychol. 12 (2), 1-9. https://doi.org/10.1590/1980-57642018dn12-020013

Davis, D.S., 2017. Ethical issues in Alzheimer's disease research involving human subjects. J. of Medical Ethics 43, 852-856. https://doi.org/10.1136/medethics-2016-103392

Doniger, G.M., Beeri, M.S., Bahar-Fuchs, A., Gottlieb, A., Tkachov, A., Kenan, H., Livny, A., Bahat, Y., Sharon, H., Ben-Gal, O., Cohen, Zeilig, M.G., Plotnik, M., 2018. Virtual reality-based cognitive-motor training for middle-aged adults at high Alzheimer's disease risk. Alzheimer's \& Dementia: Translat. Res. \& Clinical Interv. 4, 118 - 129. https://doi.org/10.1016/j.trci.2018.02.005

Drew L., 2018. An age-old story of dementia. Nature 559 (7715), S2-S3. https://doi.org/10.1038/d41586-018-05718-5

Duan, Y., Lu, L., Chen, J., Wu, C., Liang, J., Zheng, Y., Wu, J., Rong, P., Tang, C., 2018. Psychosocial interventions for Alzheimer's disease cognitive symptoms: a Bayesian network meta-analysis. BMC geriatrics, 18(1), p.175. https://doi.org/10.1186/s12877-018-0864-6

Dubey, A.K., Mewara, H.S., Gulabani, K., Trivedi, P., 2014. Challenges in design and deployment of assistive technology. In: Int. Conf. Signal Propagation and Computer Technol. (ICSPCT), Ajmer, India, 12-14 Jul 2014, pp. 466-469. https://doi.org/10.1109/ICSPCT.2014.6884992

Eberle, P., Schwarzinger, C., Stary, C., 2011. User modelling and cognitive user support: Towards structured development. Universal Access in the Info. Society 10 (3) 275-293. https://doi.org/10.1007/s10209-010-0210-z

Eisapour, M., Cao, S., Domenicucci, I., Boger, J., 2018. Participatory Design of a Virtual Reality Exercise for People with Mild Cognitive Impairment, In: Extended Abstracts of 2018 CHI Conf. on Human Factors in Comp. Sys., ACM, p. CS15, 20 April 2018. https://doi.org/10.1145/3170427.3174362

European Data Protection Supervisor, 2018. Annual Report 2017. Publications Office of the European Union, Luxembourg 2018. https://edps.europa.eu/sites/edp/files/publication/18-03-15_annual_report_2017_en.pdf (Accessed on 14 Sep. 2018)

Ferreira, F., Almeida, N., Rosa, A.F., Oliveira, A., Casimiro, J., Silva, S., Teixeira, A., 2014. Elderly centered design for interaction - The case of the S4S Medication Assistant. Procedia Comp. Sci. 27, 398-408. https://doi.org/10.1016/j.procs.2014.02.044

Fiedler, K., 2017. What constitutes strong psychological science? The (neglected) role of diagnosticity and a priori theorizing. Perspectives on Psychological Science, vol. 12, no. 1, pp. 46-61, January 2017. DOI:10.1177/1745691616654458 
Fischer, G., 2001. User Modeling in Human-Computer Interaction. User Modeling and User-Adapted Interaction 11 (1-2), 65-86 https://doi.org/10.1023/A:1011145532042

Foloppe, D.A., Richard, P., Yamaguchi, T., Etcharry-Bouyx, F., Allain, P., 2018. The potential of virtual reality-based training to enhance the functional autonomy of Alzheimer's disease patients in cooking activities: A single case study. Neuropsycholog. Rehab. 28(5), 709-33. http://dx.doi.org/10.1080/09602011.2015.1094394

García-Betances, R.I., Jiménez-Mixco, V., Arredondo, M.T., Cabrera-Umpiérrez, M.F., 2015a. Using Virtual Reality for Cognitive Training of the Elderly. Am. J. Alzheimer's Disease \& Other Dementias. 30 (1), 49-54._https://doi.org/10.1177/1533317514545866

García-Betances, R.I., Arredondo, M.T., Fico, G., Cabrera-Umpiérrez, M.F., 2015b. A Succinct Overview of Virtual Reality Technology Use in Alzheimer's Disease. Frontiers in Aging Neuroscience, 12 May 2015. https://doi.org/10.3389/fnagi.2015.00080

García-Betances, R.I., Fico, G., Salvi, D., Ottaviano, M., Arredondo, M.T., 2015c. On the convergence of affective and persuasive technologies in computer-mediated health-care systems. Human Technology 11 (1), 71-93. https://doi.org/10.17011/ht/urn.201505061741

García-Betances, R.I., Cabrera-Umpiérrez, M.F., Ottaviano, M., Pastorino, M., Arredondo, M.T., 2016. Parametric Cognitive Modeling of Information and Computer Technology Usage by People with Aging- and Disability-Derived Functional Impairments. Sensors 16 (2), 266. https://doi.org/10.3390/s16020266

García-Betances, R.I., Cabrera-Umpiérrez, M.F., Colomer, J.B.M., Castrillo, M.P., Mata, J.C., Arredondo, M.T. 2017. Smart Assistive Technologies to Enhance Well-Being of Elderly People and Promote Inclusive Communities. In: Mokhtari, M., Abdulrazak, B., Aloulou, H. (Eds.) Enhanced Quality of Life and Smart Living. ICOST 2017. Lecture Notes in Comp. Sci. 10461, 3-12. https://doi.org/10.1007/978-3-319-66188-9_1

García-Betances, R.I., 2017. A methodological framework for exploring the applicability of virtual reality in cognitive disabilities care. Doctoral Dissertation E.T.S.I. Telecomunicación, Univ. Politécnica de Madrid (UPM), Madrid, Spain, 05 Dec 2017. https://doi.org/10.20868/UPM.thesis.48687

García-Betances, R.I., Cabrera-Umpiérrez, M.F., Arredondo, M.T., 2018. Computerized neurocognitive interventions in the context of the brain training controversy. Rev. Neurosci. 29 (1), 55-69. https://doi.org/10.1515/revneuro-2017-0031

Gould, J.D., Lewis, C., 1983. Designing for usability: key principles and what designers think. In: Proc. SIGCHI Conf. Human Factors in Computing Syst., Boston, Massachusetts, USA, 12 - 15 Dec 1983, pp. 50-53. https://doi.org/10.1145/800045.801579

Gravitz, L., 2018. Drawing on the brain's resilience to fight Alzheimer's disease. Nature 559, S8-S9. https://doi.org/10.1038/d41586-01805720-X

Gregor, P., Newell, A. F., Zajicek, M., 2002. Designing for dynamic diversity: interfaces for older people. In: Assets '02, Proc. 5th Int. ACM Conf. Assistive Technol., Edinburgh, Scotland, 08-10 Jul 2002, pp. 151-156. https://doi.org/10.1145/638249.638277

Haklay, M.M., Nivala, A.-M., 2010. User-Centred Design. Chapter 5 in: Interacting with Geospatial Technologies. Wiley, pp. 89-106. https://doi.org/10.1002/9780470689813.ch5

Harte, R., Glynn, L.G., Broderick, B.J., Rodriguez-Molinero, A., Baker, P.M.A., McGuiness, B., O'Sullivan, L., Diaz, M., Quinlan, L.R., ÓLaighin, G., 2014. Human Centred Design Considerations for Connected Health Devices for the Older Adult. J. Personal. Med. 4 (2), 245-281. https://doi.org/10.3390/jpm4020245

Harvey P.D., McGurk S.R., Mahncke H. Wykes T., 2018. Controversies in Computerized Cognitive Training, Biological Psychiatry: Cognitive Neuroscience and Neuroimaging. In Press, Available online 5 July 2018, https://doi.org/10.1016/j.bpsc.2018.06.008

Hayhurst, J., 2018. How Augmented Reality and Virtual Reality is Being Used to Support People Living with Dementia-Design Challenges and Future Directions. Chapter in: Jung, T., tom Dieck, M. (Eds), Augmented Reality and Virtual Reality - Part of Progress in IS book series (PROIS). Springer, Cham, pp. 295-305. https://doi.org/10.1007/978-3-319-64027-3_20

Hendriks, A., 2007. UN Convention on the rights of persons with disabilities. Europ. J. Health Law 14, $273-298$. https://doi.org/10.1163/092902707X240620

Hodge, J., Balaam, M., Hastings, S., Morrissey, K., 2018. Exploring the Design of Tailored Virtual Reality Experiences for People with Dementia. Iin Proc. 2018 CHI Conf. Human Factors Computing Syst., ACM, $21 \quad$ Apr 2018 , paper 514. https://doi.org/10.1145/3173574.3174088

Hosking, I., Cornish, K. Bradley, M., Clarkson, P.J., 2015. Empathic engineering: helping deliver dignity through design, Journal of Medical Engineering \& Technology, 39 (7), 388-394, https://doi.org/10.3109/03091902.2015.1088090

Intraraprasit, M., Phanpanya, P. Jinjakam, C., 2017, August. Cognitive training using immersive Virtual Reality. In: 10th IEEE Biomedical Engineering International Conference (BMEiCON), Hokkaido, Japan, 31 Aug.-2 Sept. 2017. pp. 1-5. https://doi.org/10.1109/BMEiCON.2017.8229126

ISO 9241-210:2010. Ergonomics of human-system interaction -- Part 210: Human-centred design for interactive systems. Int. Standards Org., https://www.iso.org/standard/52075.html (accessed 14 Sep. 2018)

Kales, H.C., Lyketsos, C.G., Miller, E.M. and Ballard, C., 2018. Management of behavioral and psychological symptoms in people with Alzheimer's disease: an international Delphi consensus. International Psychogeriatrics, First view Published online: 02 August 2018, pp.18. https://doi.org/10.1017/S1041610218000534

Kim, H.K., Park, J., Choi, Y., Choe, M., 2018. Virtual reality sickness questionnaire (VRSQ): Motion sickness measurement index in a virtual reality environment. App. Ergonomics 69, 66-73. https://doi.org/10.1016/j.apergo.2017.12.016

Kurschl, W. Augustein, M., Burger, T., 2014. User modeling for people with special needs. Int. J. Pervasive Computing and Comm. 10 (3), 313-336, https://doi.org/10.1108/IJPCC-07-2014-0040

Lafaille-Magnan, M.-E., Poirier, J., Etienne, P., Tremblay-Mercier, J., Frenette, J., Rosa-Neto, P., Breitner, J.C.S. for the PREVENT-AD Research Group, 2017. Odor identification as a biomarker of preclinical AD in older adults at risk. Neurology 89 (4), 327-335. https://doi.org/10.1212/WNL.0000000000004159

Latham, J.R., 2014. The research canvas: A framework for designing and aligning the "DNA" of your study, (Version 2.0 ed.): Organization Design Studio ${ }^{\text {TM }}$ Ltd. Colorado Springs, Colorado, USA. https://www.drjohnlatham.com/resources/free-ebooks/research-canvas/

Learned, E.P., Christensen, C.R., Andrews, K., Book, W.D. 1969. Business Policy, Text and Cases, Irwin, R.D. Eds.

LeRouge, C., Ma, J., Sneha, S., Tolle, K., 2013. User profiles and personas in the design and development of consumer health technologies. Int. J. Medical Informat. 82 (11), e251-e268. https://doi.org/10.1016/j.ijmedinf.2011.03.006 
Lin, C.X., Lee, C., Lally, D., Coughlin, J.F., 2018. Impact of Virtual Reality (VR) Experience on Older Adults' Well-Being, in: Zhou, J., Salvendy, G., (Eds), Human Aspects of IT for the Aged Population. Applications in Health, Assistance, and Entertainment. ITAP 2018. Lecture Notes in Computer Science, 10927. pp. 89-100. https://doi.org/10.1007/978-3-319-92037-5_8

Loi, S.M., Eratne, D., Kelso, W., Velakoulis, D. and Looi, J.C., 2018. Alzheimer Disease: Non-pharmacological and pharmacological management of cognition and neuropsychiatric symptoms. Australasian Psychiatry, p.1039856218766123. https://doi.org/10.1177/1039856218766123

Lokka, I.E., Çöltekin, A., Wiener, J., Fabrikant, S.I. Röcke, C., 2018. Virtual environments as memory training devices in navigational tasks for older adults. Scientific reports 8, 10809. https://doi.org/10.1038/s41598-018-29029-x

Ma, Q., Chen, K., Chan, A.H.S., Teh, P.-L., 2015. Acceptance of ICTs by Older Adults: A. Review of Recent Studies. In: Zhou J. \& Salvendy G. (Eds.), Human Aspects of IT for the Aged Population. Design for Aging. ITAP 2015. Lect. Notes in Comp. Sci., 9193, $239-249$. https://doi.org/10.1007/978-3-319-20892-3_24

Marron, E.M., Viejo-Sobera, R., Quintana, M., Redolar-Ripoll, D., Rodríguez, D., Garolera, M., 2018. Transcranial magnetic stimulation intervention in Alzheimer's disease: a research proposal for a randomized controlled trial. BMC research notes, 11(1), p.648. https://doi.org/10.1186/s13104-018-3757-z

McCabe, J.A., Redick, T.S., Engle, R.W., 2016. Brain-Training Pessimism, but Applied-Memory Optimism. Psychol. Sci. in the Public Interest, 17 (3), pp. 187-191. https://doi.org/10.1177/1529100616664716

Monaco, A., Sforza, G., Amoroso, N., Antonacci, M., Bellotti, R., de Tommaso, M., Di Bitonto, P., Di Sciascio, E., Diacono, D., Gentile, E. Montemurno, A., 2018. The PERSON project: a serious brain-computer interface game for treatment in cognitive impairment. Health and Technology, 1-11, First Online: 10 September 2018. https://doi.org/10.1007/s12553-018-0258-y

Mondellini, M., Arlati, S., Pizzagalli, S., Greci, L., Sacco, M., Ferrigno, G., 2018. Assessment of the usability of an immersive virtual supermarket for the cognitive rehabilitation of elderly patients: A pilot study on young adults. In: Proc. IEEE 6th Int. Conf. Serious Games and Appl. for Health (SeGAH), Vienna, Austria, 16 May 2018. https://doi.org/10.1109/SeGAH.2018.8401313

Monteagudo, J.L., 2012. Capacidades y Oportunidades de Innovación en TIC para Alzheimer. Unidad de Investigación en Telemedicina, Instituto de Salud Carlos III, Madrid, Spain. http://vodafone.es/static/fichero/pro_ucm_mgmt_546171.pdf (accessed 14 Sep. 2018)

Hauk, N., Hüffmeier, J., Krumm, S., 2018. Ready to be a Silver Surfer? A Meta-analysis on the Relationship Between Chronological Age and Technology Acceptance. Comp. in Human Behav. 84, 304-319. https://doi.org/10.1016/j.chb.2018.01.020

Nebel, R., 2018. Why Sex Matters in Alzheimer's. Scientific American 319, 11-11. https://doi.org/10.1038/scientificamerican0918-11

Newell N., P. Gregor, P., 1997. Human computer interfaces for people with disabilities. Chapter 35 in M. Helander, T. Landauer, \& P. Prabhu (Eds.), Handbook of Human-Computer Interaction. 2nd. Ed. North-Holland, pp. 813-824. https://doi.org/10.1016/B978-044481862$1.50101-1$

Nguyen, J.-P., Suárez, A., Kemoun, G., Meignier, M., Le Saout, E., Damier, P., Nizard, J., Lefaucheure, J.-P., 2017. Repetitive transcranial magnetic stimulation combined with cognitive training for the treatment of Alzheimer's disease, Neurophysiol. Clinique / Clinical Neurophysiol. 47 (1), 47-53. https://doi.org/10.1016/j.neucli.2017.01.001

NIA, 2018. Alzheimer's Disease Fact Sheet. National Institute on Aging. National Institute of Health, U.S. Department of Health \& Human Services. https://www.nia.nih.gov/health/alzheimers-disease-fact-sheet (accessed 14 Sep. 2018)

Norman, D.A., Draper, S.W., 1986 User centered system design. New Perspectives on Human-Computer Interaction, L. Erlbaum Associates Inc., Hillsdale, NJ, USA, 1986.

Preece, J., Sharp,H., Rogers, Y., 2015. Interaction design: beyond human-computer interaction (4th Edition). John Wiley \& Sons, Inc., Aug 2015. ISBN: 978-1-119-08879-0

Serino, S., Morganti, F., Colombo, B., Pedroli, E., Cipresso, P., Riva, G., 2018. Disentangling the Contribution of Spatial Reference Frames to Executive Functioning in Healthy and Pathological Aging: An Experimental Study with Virtual Reality. Sensors 18 (6), 1783. https://doi.org/10.3390\%2Fs18061783

Raggi, A., Tasca, D., Ferri, R., 2017. A brief essay on non-pharmacological treatment of Alzheimer's disease. Rev. in the Neurosci. 28 (6), 587-597. https://doi.org/10.1515/revneuro-2017-0002

Richard P., Foloppe D., Allain P., 2018. A Virtual Kitchen for Cognitive Rehabilitation of Alzheimer Patients," In 2018 International Conference on Human Interface and the Management of Information, HIMI 2018, Yamamoto S., Mori H. (eds.) Human Interface and the Management of Information. Interaction, Visualization, and Analytics, pp. 426-435, Lecture Notes in Computer Science book series, vol. 10904, Springer, Cham. https://doi.org/10.1007/978-3-319-92043-6_36

Rizzo, A., Schultheis, M.T., Rothbound, B.O., 2002. Ethical issues for the use of virtual reality in the psychological sciences" Chapter 12 in: Bush, S.S., and Brexler, M.L. (Eds.), Ethical Issues in Clinical Neuropsychology, Swets \& Zeitlinger Plub. p. 243. ISBN: 9026519249

Rizzo, A., Kim, G.J., 2005. A SWOT analysis of the field of virtual reality rehabilitation and therapy. Presence: Teleoperators and Virtual Environments 14 (2), 119-146. https://doi.org/10.1162/1054746053967094

Robillard, J.M., Hoey, J., 2018. Emotion and Motivation in Cognitive Assistive Technologies for Dementia. Computer 52 (3), $24-34$. https://doi.org/10.1109/MC.2018.1731059

Rodakowski, J., Reynolds III, C.F., Lopez, O.L., Butters, M.A., Dew, M.A. Skidmore, E.R., 2018. Developing a Non-Pharmacological Intervention for Individuals With Mild Cognitive Impairment. Journal of Applied Gerontology, 37(5), 665-676. https://doi.org/10.1177/0733464816645808

Rose, T., Nam, C.S., Chen, K.B., 2018. Immersion of virtual reality for rehabilitation - Review. Appl. Ergonomics. 69, $153-161$. https://doi.org/10.1016/j.apergo.2018.01.009

Savulich, G., Piercy, T., Fox, C., Suckling, J., Rowe, O’Brien, J.T., Sahakian, B.J., 2017. Cognitive Training Using a Novel Memory Game on an iPad in Patients with Amnestic Mild Cognitive Impairment (aMCI). Int. J. of Neuropsychopharma. 20 (8), $624-633$. https://doi.org/10.1093/ijnp/pyx040

Schraepen, B., Abeele, V.V., Huygelier, H., Gillebert, C.R., Van Ee, R., 2017. Attitudes towards and Usability of Head-mounted Virtual Reality in Older Adults. In: Extended Abstracts of the CHI PLAY, 15 - 18 Oct 2017, Amsterdam, The Netherlands. https://lirias.kuleuven.be/retrieve/480712 
Schulz, K.F., Altman, D.G., Moher, D. for the CONSORT Group, CONSORT 2010 Statement: updated guidelines for reporting parallel group randomised trials, the BMJ 340 (c332), 24. https://doi.org/10.1136/bmj.c332

Simons, D.J., Boot, W.R., Charness, N., Gathercole, S.E., Chabris, C.F., Hambrick, D.Z., Stine-Morrow, E.A.L., 2016. Do 'Brain-Training' Programs Work? Psychol. Sci. in the Public Interest 17 (3), 103-18. https://doi.org/10.1177/1529100616661983

Song, W., Sakao T., 2017. A customization-oriented framework for design of sustainable product/service systems. J. of Cleaner Production, 140 (3),1672-1685. DOI:10.1016/j.jclepro.2016.09.111

Stockdale, R., Standing, C., 2006. An interpretive approach to evaluating information systems: A content, context, process framework, Europ. J. of Operational Res. 173 (3), 1090-1102. https://doi.org/10.1016/j.ejor.2005.07.006

Vaughan, N., Gabrys, B., Dubey, V.N., 2016. An overview of self-adaptive technologies within virtual reality training. Computer Sci. Rev. 22, 65-87. https://doi.org/10.1016/j.cosrev.2016.09.001

Vos, T.E.J., Marín, B., Escalona, M.J., Marchetto, A., 2012. A methodological framework for evaluating software testing techniques and tools. In Proc. IEEE 12th Int. Conf. Quality Software (QSIC), Xi'an, Shaanxi, China, 27-29 Aug. 2012, pp. 230-239. https://doi.org/10.1109/QSIC.2012.16

Wagner, N., Hassanein, K., Head, M., 2010. Computer use by older adults: A multi-disciplinary review. Comp. in Human Behavior 26 (5), 870-882._https://doi.org/10.1016/j.chb.2010.03.029

WCAG, 2008. Web Content Accessibility Guidelines (WCAG) 2.0, W3C Recommendation, Dec 2008. https://www.w3.org/TR/WCAG20/ (accessed 14 Sep. 2018)

WHO 1980. International classification of impairments, disabilities, and handicaps: a manual of classification relating to the consequences of disease, published in accordance with resolution WHA29.35 of the Twenty-ninth World Health Assembly, May 1976. Geneva: World Health Organization. http://www.who.int/iris/handle/10665/41003 (accessed 14 Sep. 2018)

WHO - ICF, 2001. International Classification of Functioning, Disability and Health (ICF). Endorsed in the Fifty-fourth World Health Assembly, 22 May 2001 (resolution WHA 54.21), World Health Organization, http://www.who.int/classifications/icf/icf_more/en/

Woodward, M.R., Hafeez, M.U., Qi, Q., Riaz, A., Benedict, R.H.B., Yan, L., Szigeti, K., 2018. Odorant Item Specific Olfactory Identification Deficit May Differentiate Alzheimer Disease From Aging. The American Journal of Geriatric Psychiatry, 26(8), 835-846.

https://doi.org/10.1016/j.jagp.2018.02.008 


\section{Biographies}

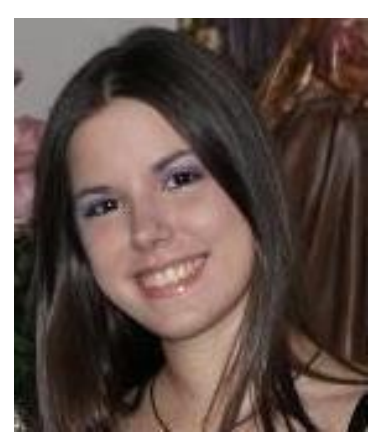

Rebeca Isabel García-Betances is a Telecommunications Engineer with a Master's degree (with honors) in Biomedical Engineering. In 2017 she received the Doctorate in Biomedical Engineering degree (cum laude) from Universidad Politécnica de Madrid (UPM), Spain. She presently is a senior researcher at the Life Supporting Technologies Group (LifeSTech)

(https://www.lst.tfo.upm.es/rebeca-garcia/) of UPM's Escuela Técnica Superior de Ingenieros de Telecomunicación (ETSIT). She has worked on telemedicine, patient management, e-Health, eInclusion, self-management of chronic diseases, and Ambient Intelligence applications. Currently she is involved in activities related to healthcare of neurodegenerative cognitive disabilities, humancomputer interfaces, and smart home technologies. Dr. García-Betances has published work about rural telemedicine communications networks infrastructure, automatic QR code patient identification, patient engagement in chronic illness self-management, affective and persuasive computer-mediated healthcare, application of ICTs to aging- and disability-derived functional impairments, including VR-based healthcare interventions (https://www.lst.tfo.upm.es/virtual-reality-room/) for the elderly and for cognitively impaired patients. She has authored a book chapter and around twenty publications in refereed specialized technical journals and conferences.

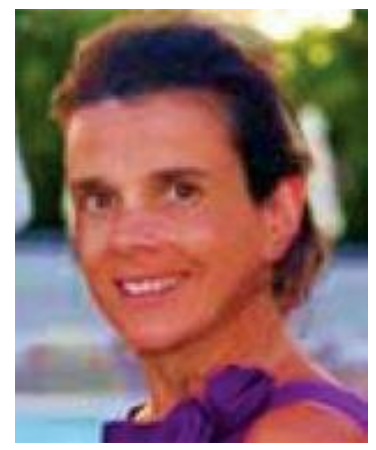

María Fernanda Cabrera-Umpiérrez is a Telecommunications Engineer with a Ph.D. in Biomedical Engineering. She is an associate professor at the Bioengineering and Photonics Department of ETSIT, UPM, and is the current CTO of the LifeSTech Group (https://www.lst.tfo.upm.es/mafernanda-cabrera/). She has been involved in EU research programs since 1998 and has been responsible for concept development and coordination of numerous large multi-disciplinary local and international projects. She has participated in over $30 \mathrm{EU}$ projects, and has acted as project coordinator, technical or quality manager of 4 research projects funded by the European Commission. Her main field of expertise covers a broad range of applications in the domains of ICTs applications for health and social inclusion, including services and content personalization, ambient intelligence framework services, application development for mobile phones, and ICT accessibility. Dr. CabreraUmpiérrez has authored more than a hundred articles in refereed national and international journals and conferences in the fields of e-Health, adaptive interfaces and decision support, as well as integrated care.

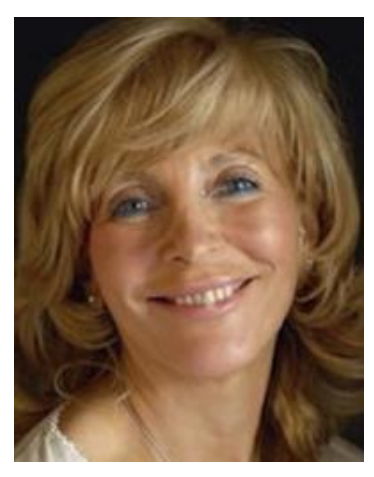

María Teresa Arredondo Waldmeyer was the first woman to receive the degree of Electrical Engineer from the Universidad Nacional de Tucumán, Argentina. She was a founder in 1977 of the Argentinean Society of Biomedical Engineering (SABI), and its first Secretary. In 1988 she obtained the first Ph.D. degree in Telecommunications Engineering granted by Universidad Politécnica de Valencia (UPV), Spain. In 2001 she became the first female Full Professor of Telecommunications and Bioengineering in Spain. She currently is a faculty member of the Bioengineering and Photonics Department of ETSIT (UPM), as well as the CEO of the LifeSTech Group (https://www.lst.tfo.upm.es/ma-teresa/), which she founded in 1995. Among LifeSTech's many activities are those of the "Madrid Smart House Living Lab," (https://www.lst.tfo.upm.es/livinglabs/) located at ETSIT (UPM) in the Madrid-Moncloa Campus. Prof. Arredondo Waldmeyer is also the Director of Latin-American Affairs at UPM, and since 2002 she heads the Vodafone UPM's Chair for Healthcare and e-Inclusion. 